\title{
A Universal Electrolyte Formulation for the Electrodeposition of Pristine Carbon and Polypyrrole Composites for Supercapacitors
} DOI:

10.1021/acsami.0c01216

\section{Document Version \\ Accepted author manuscript}

Link to publication record in Manchester Research Explorer

Citation for published version (APA):

Ji, S., Yang, J., Cao, J., Zhao, X., Mohammed, M. A., He, P., Dryfe, R. A. W., \& Kinloch, I. A. (2020). A Universal Electrolyte Formulation for the Electrodeposition of Pristine Carbon and Polypyrrole Composites for

Supercapacitors. ACS Applied Materials and Interfaces, 12(11), 13386-13399.

https://doi.org/10.1021/acsami.0c01216

\section{Published in:}

ACS Applied Materials and Interfaces

\section{Citing this paper}

Please note that where the full-text provided on Manchester Research Explorer is the Author Accepted Manuscript or Proof version this may differ from the final Published version. If citing, it is advised that you check and use the publisher's definitive version.

\section{General rights}

Copyright and moral rights for the publications made accessible in the Research Explorer are retained by the authors and/or other copyright owners and it is a condition of accessing publications that users recognise and abide by the legal requirements associated with these rights.

\section{Takedown policy}

If you believe that this document breaches copyright please refer to the University of Manchester's Takedown Procedures [http://man.ac.uk/04Y6Bo] or contact uml.scholarlycommunications@manchester.ac.uk providing relevant details, so we can investigate your claim.

\section{OPEN ACCESS}




\section{A universal electrolyte formulation for the electrodeposition of pristine carbon and polypyrrole composites for supercapacitors}

Shiyu Ji, Jie Yang, ${ }^{\not}, \S$ Jianyun Cao, ${ }^{*}{ }^{\dagger}, \S$ Xin Zhao, ${ }^{\dagger}, \|$ Mahdi A. Mohammed, ${ }^{\dagger}$ Pei He, ${ }^{\dagger}, \perp$, Robert A. W. Dryfe, ${ }^{*, \xi}$ and Ian A. Kinloch, $* \neq, \S$

${ }^{\dagger}$ Department of Materials, University of Manchester, Oxford Road, Manchester, M13 9PL, U.K.

$\$$ Department of Chemistry, University of Manchester, Oxford Road, Manchester M13 9PL, U.K.

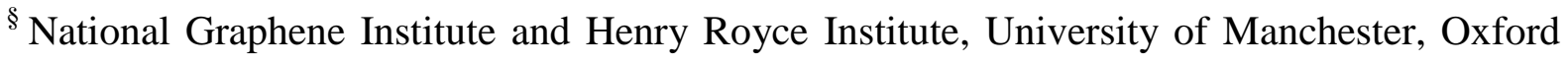
Road, M13 9PL, U.K.

॥ Shenzhen Institute of Advanced Graphene Application and Technology, Shenzhen, Guangdong, 518106, China

$\perp$ School of Physics and Electronics, Central South University, Changsha, Hunan, 410083, China

KEYWORDS: electrodeposition; polypyrrole; graphene; carbon nanotube; carbon black; composite; supercapacitor 


\section{ABSTRACT}

The electrodeposition of conducting polymer-carbon composites from an electrolyte precursor solution is a facile one-step approach to fabricate device-ready electrodes for energy storage. A key challenge in this approach is the dispersion of the carbon nanomaterials with the aqueous precursor solution, with previous approaches either heavily oxidising the carbon nanomaterials or using high concentrations of anionic surfactants as dopants. However, the former reduces the electrical conductivity of carbon whilst the latter reduces the ionic mobility of the PPy due to the large anion size. Herein, for the first time we present a quaternary electrolyte formulation for the fabrication of pristine carbon and polypyrrole (PPy) composites does not sacrifice either electron or ion mobility. The electrolyte uses lithium perchlorate $(20 \mathrm{mM})$ as a supporting electrolyte and dopant, sodium dodecylbenzenesulfonate at a very low concentration $(1.43 \mathrm{mM})$ as a surfactant, together with pristine carbon nanomaterials and pyrrole monomers. The order of magnitude difference between the concentration of the dopant and surfactant ion allows the as-deposited PPy to be doped predominantly by small sized and mobile perchlorate anions. Composites of PPy with carbon black, carbon nanotubes and electrochemical exfoliated graphene (EEG) have been successfully prepared using this new quaternary electrolyte. The as-fabricated PPy/EEG composite electrodes showed a specific capacitance of $348.8 \mathrm{~F} \mathrm{~g}^{-1}$, with high rate capability $\left(190.7 \mathrm{~F} \mathrm{~g}^{-1}\right.$ at $\left.71 \mathrm{~A} \mathrm{~g}^{-1}\right)$. Supercapacitor devices based on the PPy/EEG composite electrodes exhibit high rate behavior up to $500 \mathrm{mV} \mathrm{s}^{-1}$, and a long cycle life of 5000 cycles. 


\section{Introduction}

Conducting polymers, including polypyrrole, polyaniline, polythiophene and their derivatives, have attracted tremendous research interest due to their promising electrical conductivity and electroactivity. A wide range of applications have been discovered for conducting polymers, including batteries, supercapacitors, sensors, thermoelectric and electrochromic devices, anti-static and anti-corrosion coatings. ${ }^{1-4}$ Supercapacitors, as a type of energy storage device, featuring fast charge-discharge rate (from seconds to minutes), high power density and long cycling stability, have been widely used when a short-term, fast energy uptake or delivery is required. ${ }^{5-6}$ However, the energy density of supercapacitors is far away from that of lithium-ion batteries, and supercapacitors' key merit of high power is now facing challenges from the development of high-rate batteries. ${ }^{7-9}$ The application of conducting polymers in supercapacitors is expected to help bridge this energy density gap between carbon-based supercapacitors and batteries whilst maintaining their high-power. In order to achieve this target, both fast electron and ion transfer in the electrode are essential.

Among the widely used conducting polymers, polypyrrole (PPy) is low in cost, high in specific capacitance $\left(640 \mathrm{~F} \mathrm{~g}^{-1}\right)$ and possesses good electrical conductivity $\left(10-50 \mathrm{~S} \mathrm{~cm}^{-1}\right)$ in a doped state. ${ }^{1-2}$ In addition, the pyrrole monomer has good solubility in water and thus can be polymerized in aqueous media. ${ }^{10}$ Similar to other conducting polymers, the charge storage mechanism of PPy involves the insertion and de-insertion of electrolyte anions into the polymer chains, causing volume swelling and shrinkage. ${ }^{1}$ This volume change leads to poor 
cycling stability for PPy electrodes. ${ }^{11}$ In addition, the densely grown PPy film/coating via electrodeposition inhibits the migration of electrolyte ions through the thickness of electrode, leading to sluggish performance at high rates. ${ }^{11}$

Compositing conducting polymers with carbon nanomaterials, including carbon nanotubes (CNTs) and graphene, is an attractive solution to overcome the intrinsic disadvantages of conducting polymers. ${ }^{1,3-4}$ For example, the mechanical support provided by the carbon minimizes the electrode degradation caused by the volume changes during cycling. ${ }^{11}$ In addition, carbon nanomaterials with one-dimensional (1D, CNTs) or two-dimensional (2D, graphene) morphology, can act as templates to direct the nucleation and growth of the conducting polymer, leading to a porous structure and improving the migration of the electrolyte ions. ${ }^{12-13}$ Moreover, the carbon nanomaterials could provide fast electron transport routes when the conducting polymer is in an un-doped state.

Typically, in-situ polymerization has been used for the preparation of conducting polymer/carbon composites. ${ }^{4}$ This procedure involves dispersing of carbon nanomaterials in a solvent in which the monomer was dissolved and then either adding polymerization reagents (chemical polymerization) or applying an electric current (electrochemical polymerization). The electrochemical co-deposition of both the conducting polymer and carbon nanomaterial to form a composite has drawn significant research attention over the past two decades due to its ability to make electrodes in one-step. ${ }^{11-22}$ 
Ideally, the precursor solution consists of three components: the pyrrole monomer; carbon nanomaterial and supporting electrolyte. The supporting electrolyte provides solution conductivity to make the electrodeposition possible. The anions of supporting electrolyte are simultaneously doped into the PPy polymer chains during polymerization to balance the positive charges. However, this approach is complicated by the need to obtain a stable dispersion of carbon nanomaterial in the electrolyte precursor solution. To the best of our knowledge, the majority of the previous reports have achieved this through two approaches: (1) oxidizing the carbon nanomaterials or (2) using large anionic surfactants as both dispersion aids for the carbon nanomaterial and dopants for the PPy.

The oxidation of carbon nanomaterials is most widely used, with the resulting oxygen surface groups enabling a good dispersion in water. ${ }^{11-13,16-18, ~ 20,22-23}$ However, the large degree of functionalization required to ensure aqueous dispersion forms materials such as graphene oxide (GO), meaning that the carbons have poor electrical conductivity due to the disruption of their conjugated structure. Thus the high power performance of the conducting polymer/carbon composites is compromised when used as electrodes for supercapacitors. (It should be noted though that one benefit of this approach is that oxidized carbon nanomaterials can also act as the supporting electrolyte, leading to a binary precursor solution with no supporting ions. ${ }^{13,17}$ ) The use of anionic surfactants as supporting electrolyte in the precursor solution has assisted 
the dispersion of the carbon nanomaterials in aqueous media without the need of harsh oxidation to introduce oxygen groups. ${ }^{19,24}$ For example, sodium dodecyl benzenesulfonate (SDBS) has been used as both surfactant and supporting electrolyte for the electrodeposition of reduced GO and PPy composite electrodes. ${ }^{19}$ However, the dodecyl benzenesulfonate anion $\left(\mathrm{DBS}^{-}\right)$with its large size has poor mobility once being doped (inserted) into the polymer chain to balance the positive charge during the electrochemical polymerization process. ${ }^{15,25}$ This leads to a sluggish charge-discharge process as the large $\mathrm{DBS}^{-}$anion cannot be efficiently de-inserted from the bulk polymer. Previously reports suggests that the composite of PPy and functionalized single wall CNTs with $\mathrm{DBS}^{-}$anion as dopant shows poor capacitive behavior in $3 \mathrm{M} \mathrm{KCl}$ aqueous electrolyte. ${ }^{15}$ Therefore, the further development of high performance PPy and pristine carbon composites has been inhibited by the conflicting effects of anionic surfactant. In summary, both previous approaches to disperse the carbon nanomaterials have comprised the final capacitor performance - the oxidation reduces the electrical conductivity whilst the use of concentrated surfactant solution reduces the ion mobility of as-deposited PPy.

Herein, we present a quaternary electrolyte formulation to solve the conflicting effects of anionic surfactant. $\mathrm{LiClO}_{4}(20 \mathrm{mM})$ has been used as the predominant component of the supporting electrolyte as well as dopant; SDBS at a low concentration of $1.4 \mathrm{mM}\left(0.5 \mathrm{mg} \mathrm{mL}^{-1}\right)$ is used as a surfactant; together with pristine carbon nanomaterials and pyrrole monomers. The minimal amount of SDBS used assists the dispersion of carbons without compromising the electrochemical performance of the as-deposited PPy. Composites of PPy and 
electrochemically exfoliated graphene (EEG), carbon nanotubes (CNTs) and carbon black (CB) have been successfully fabricated. In addition, we have demonstrated the ability to tune the composition and morphology of the as-deposited PPy and EEG composites via control the EEG concentration in the precursor electrolyte. As a result, the as-fabricated PPy/EEG composite electrodes show a high specific capacitance of $348.8 \mathrm{~F} \mathrm{~g}^{-1}$, with good rate capability

(190.7 $\mathrm{F} \mathrm{g}^{-1}$ at $71 \mathrm{~A} \mathrm{~g}^{-1}$ ). The as-fabricated aqueous and solid-state supercapacitors based on PPy/EEG composite electrodes exhibit high rate performance up to $500 \mathrm{mV} \mathrm{s}^{-1}$, with good cycling stability up to $93.4 \%$ retention after 5000 cycles. This quaternary electrolyte formulation can be potentially applied to the electrodeposition of other conducting polymer (e.g. polyaniline) based composites for diverse applications.

\section{Experimental Section}

Materials. Graphite foil for the preparation of EEG was purchased from Gee Graphite LTD (Dewsbury, England). CNTs (multi-walled; $\geq 98$ wt. $\%$ carbon content; O.D $\times$ I.D $\times$ L $=10 \mathrm{~nm}$ $\pm 1 \mathrm{~nm} \times 4.5 \mathrm{~nm} \pm 0.5 \mathrm{~nm} \times 3 \sim 6 \mu \mathrm{m}$, CAS: 308068-56-6) were purchased from Sigma-Aldrich (Gillingham, Dorset, UK). CB (Vulcan XC72) was ordered from Cabot Corporation. Pyrrole (regent grade, 98\%) was purchased from Sigma-Aldrich (Gillingham, Dorset, UK). All other chemicals were purchased from Sigma-Aldrich (Gillingham, Dorset, UK)

Preparation of EEG. Electrochemical exfoliation has been demonstrated by several groups 
worldwide to be a low cost, scalable and environmentally friendly way to produce graphene derived materials, including $\mathrm{EEG},{ }^{26-27}$ and electrochemical graphene oxide (EGO). ${ }^{28-29}$ Typically, EEG is produced by direct exfoliation of graphite raw material in aqueous acidic or neutral electrolyte with a bias voltage from 5 to $10 \mathrm{~V}^{26}$ The as-produced EEG with a low oxygen content and good electrical conductivity is a promising candidate for the conducting polymer/carbon composites. ${ }^{26-27,30}$ To produce EEG, graphite foil was directly used as the anode in a two-electrode configuration with a piece of $\mathrm{Pt}$ mesh as counter electrode, and $0.1 \mathrm{M}$ aqueous ammonium sulfate as electrolyte. The exfoliation was carried out at a constant voltage of $10 \mathrm{~V}$ using a direct current power supply (GW INSTEK, Taiwan). The exfoliated product was washed with deionized water for 5 times. The washed product was dispersed in N,N'-dimethylformamide by bath sonication (Elmasonic P $70 \mathrm{H}$, Germany) for $30 \mathrm{~min}$ at $80 \%$ power and then settled under ambient conditions for $24 \mathrm{~h}$ to precipitate the un-exfoliated graphite. Exfoliated graphene was then separated from the supernatant by filtration and washed with deionized water for 3 times. Finally, the filtered EEG was freeze dried and stored for further use. According to our previous report, ${ }^{30}$ the as-prepared EEG contains 9.36 at.\% of oxygen (C/O ratio 9.6), which is comparable with that of the reduced graphene oxide. ${ }^{31}$

Electrochemical deposition of pristine carbon and PPy composite electrodes. The as-prepared EEG was firstly dispersed in $20 \mathrm{mM} \mathrm{LiClO}_{4}$ aqueous solution with the assistance of SDBS $\left(0.5 \mathrm{mg} \mathrm{mL}^{-1}, 1.43 \mathrm{mM}\right)$ by sonicating in an ultrasonic bath (Elmasonic P $70 \mathrm{H}$, Germany) for $30 \mathrm{~min}$ at $80 \%$ power. The dispersion was then settled for $24 \mathrm{~h}$ and the 
supernatant was collected for the further use (the purpose of this is to further separate the thick and un-exfoliated graphite). CNTs and CB were used as purchased without any treatment. The CNTs or CB were dispersed in $20 \mathrm{mM} \mathrm{LiClO}_{4}$ and $0.5 \mathrm{mg} \mathrm{mL}^{-1} \mathrm{SDBS}$ aqueous solution by bath sonication for $30 \mathrm{~min}$.

The as-obtained dispersions were used for the formulation of the precursor solution for the electrochemical deposition of PPy/EEG, PPy/CNTs and PPy/CB composites. Typically, the electrolyte precursor solution consisted of $72 \mathrm{mM}$ of pyrrole momomer, $20 \mathrm{mM} \mathrm{LiClO}_{4}, 0.5$ $\mathrm{mg} \mathrm{mL} \mathrm{m}^{-1}$ SDBS and $0.1 \mathrm{mg} \mathrm{mL}^{-1}$ carbon nanomaterial. A three-electrode configuration was used for the deposition with a piece of $\mathrm{Ti}$ foil as the working electrode, a SCE reference electrode and a Pt counter electrode. The electrodeposition was conducted using an IviumStat potentiostat at a constant potential of $0.8 \mathrm{~V}$. The deposition time kept at $600 \mathrm{~s}$ if not specified. After deposition, the composite electrode was rinsed with deionized water 3 times and then stored in $1 \mathrm{M} \mathrm{KCl}$ aqueous solution or deionized water for further use.

Materials characterization. Samples for the characterization were thoroughly rinsed with deionized water and then dried at $80{ }^{\circ} \mathrm{C}$ for $10 \mathrm{~h}$. Scanning electron microscopy (SEM, Philips XL30 FEGSEM) and transmission electron microscopy (TEM, Philips CM20) were used to characterize the morphologies of the composites. Fourier transform infrared spectra (FT-IR) were measured with a Nicolet 5700 spectrometer. X-ray photoelectron spectroscopy (XPS) was performed with a Kratos Axis Ultra X-ray photoelectron spectrometer meter; curve fitting 
was accomplished by CasaXPS software. Thermal gravimetric analysis (TGA) was performed on a Jupiter Netzsch STA 449 C instrument in argon atmosphere from room temperature to $500{ }^{\circ} \mathrm{C}$ with a ramp rate of $10{ }^{\circ} \mathrm{C} \mathrm{min}^{-1}$. Nitrogen adsorption isotherms were performed with a Micromeritics TriStar II Plus. The specific surface area and pore size distribution were derived by using the Brunauer-Emmett-Teller (BET) model and density functional theory (DFT) model, respectively. $^{32-33}$

Electrochemical measurements. Electrochemical performance of individual electrodes was firstly studied by a three -electrode configuration with the PPy/carbon composite as working electrode, SCE as reference electrode and $\mathrm{Pt}$ as counter electrode. For the aqueous two-electrode device, two identical PPy/carbon composite electrodes were assembled into a supercapacitor device with a piece of PTFE filter membrane as separator and $1 \mathrm{M} \mathrm{KCl}$ as electrolyte. For solid-state supercapacitor, $1 \mathrm{M} \mathrm{LiCl} /$ polyvinyl alcohol (PVA) gel was used as electrolyte. The LiCl/PVA gel was prepared by dissolving $5 \mathrm{~g}$ PVA into $50 \mathrm{~mL} 1 \mathrm{M} \mathrm{LiCl}$ aqueous solution at $80{ }^{\circ} \mathrm{C}$. For the device fabrication, two PPy/carbon composite electrodes and a piece of PTFE filter membrane were soaked into the gel electrolyte for $2 \mathrm{~h}$ and then solidified at room temperature for $4 \mathrm{~h}$ before assembling. All electrochemical measurements were conducted with an IviumStat electrochemical workstation.

For the three-electrode configuration, the areal capacitances $\left(C_{A}\right)$ of the electrodes were calculated from the galvanostatic charge-discharge results as follows: 


$$
C_{A}=\frac{I \Delta t}{A \Delta V}
$$

where $I$ is the discharge current density, $\Delta t$ is the discharge time, $A$ is the area of the electrodes; $\Delta V$ is the potential range exclude the IR drop. The specific capacitances $\left(C_{S}\right)$ were calculated by dividing $C_{A}$ with the mass loadings $(m)$ of the electrodes.

For two-electrode supercapacitor devices, the areal capacitance for each electrode was calculated as:

$$
C_{A}=2 C_{c e l l}=2 \frac{I \Delta t}{A \Delta V}
$$

where $C_{c e l l}$ is the areal capacitance of the device, a coefficient of 2 was used to normalize the areal capacitance of the device to the a single electrode. The areal energy density $(E)$ was obtained from:

$$
E=\frac{1}{2} C_{c e l l} V^{2}
$$

where $V$ is the cell voltage of the supercapacitor excluded the IR drop. The areal power density $(P)$ was calculated via:

$$
P=\frac{E}{\Delta t}
$$

\section{Results and discussion}

Figure 1 illustrates the process for the electrochemical deposition of the pristine carbon and PPy composites. The quaternary electrolyte precursor solution (Figure 1a) contains $\mathrm{LiClO}_{4}(20$ $\mathrm{mM})$ as supporting electrolyte and dopant, SDBS $\left(0.5 \mathrm{mg} \mathrm{mL} \mathrm{m}^{-1}, 1.43 \mathrm{mM}\right)$ as surfactant, together with pristine carbon nanomaterial $\left(0.1 \mathrm{mg} \mathrm{mL}^{-1}\right)$ and pyrrole monomer $(72 \mathrm{mM})$. 
Figure $1 b$, c and d display the schematic illustrations (left) and SEM images (right) for the as-deposited $\mathrm{PPy} / \mathrm{CB}, \mathrm{PPy} / \mathrm{CNTs}$ and $\mathrm{PPy} / \mathrm{EEG}$ composites, respectively.

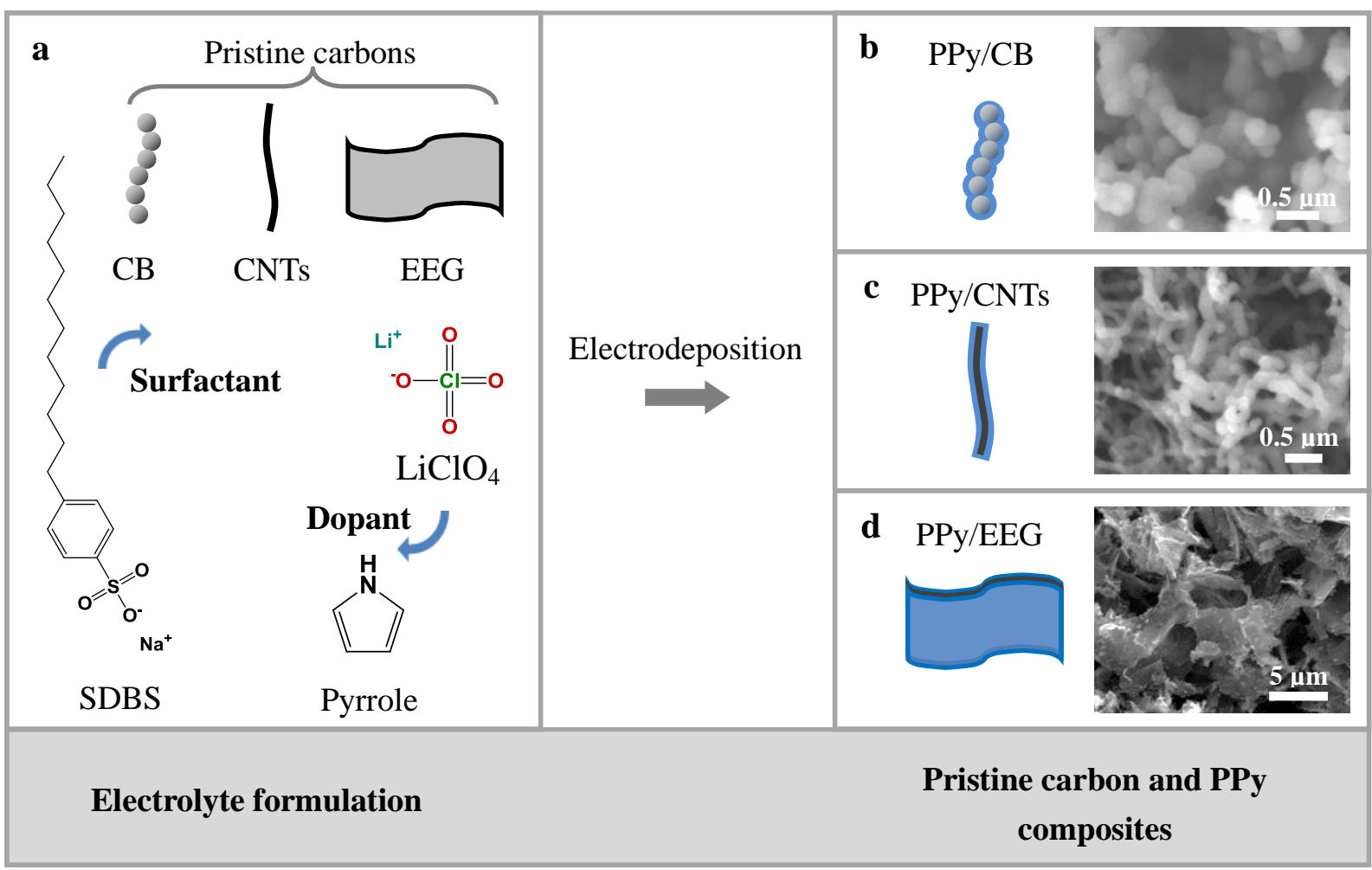

Figure 1. Schematic illustrating the electrochemical deposition of pristine carbon and PPy composites. (a) Schematic of the quaternary formulation for the electrolyte precursor solution. (b), (c) and (d) schematics and SEM images for the as-deposited PPy/carbon black (CB), PPy/carbon nanotubes (CNTs) and PPy/electrochemically exfoliated graphene (EEG) composites, respectively.

The effect of electrolyte formulation on the structure and electrochemical performance of the as-deposited electrodes have been studied by using the electrodeposition of PPy/EEG composite as an exemplar system. Table 1 shows the formulations of different electrolyte precursor solutions. As shown in Figure 2a, with a SDBS concentration of $0.5 \mathrm{mg} \mathrm{mL}^{-1}$, the 
EEG aqueous dispersion remains stable after $24 \mathrm{~h}$, which is long enough to conduct the electrodeposition process. In contrast, EEG dispersed in $20 \mathrm{mM} \mathrm{LiClO}_{4}$ without SDBS aggregates and precipitates after $24 \mathrm{~h}$. This result suggests that SDBS with a concentration of $0.5 \mathrm{mg} \mathrm{mL}^{-1}$ is sufficient to stabilize EEG in the precursor solution.

$\mathbf{a}$

Just sonicated

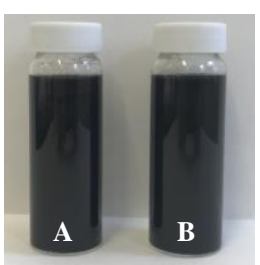
A: $\mathrm{EEG}+20 \mathrm{mM} \mathrm{LiClO}_{4}$
B: $\mathrm{EEG}+20 \mathrm{mM} \mathrm{LiClO}_{4}+0.5 \mathrm{mg} \mathrm{mL}{ }^{-1} \mathrm{SDBS}$

c

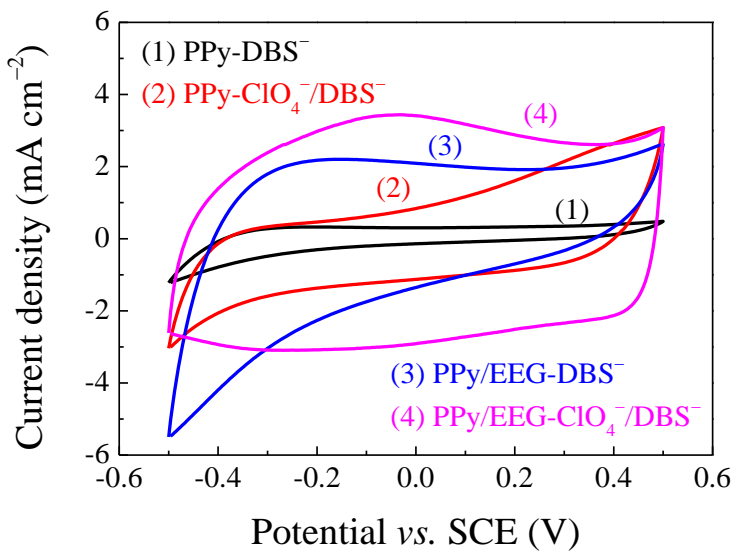

b

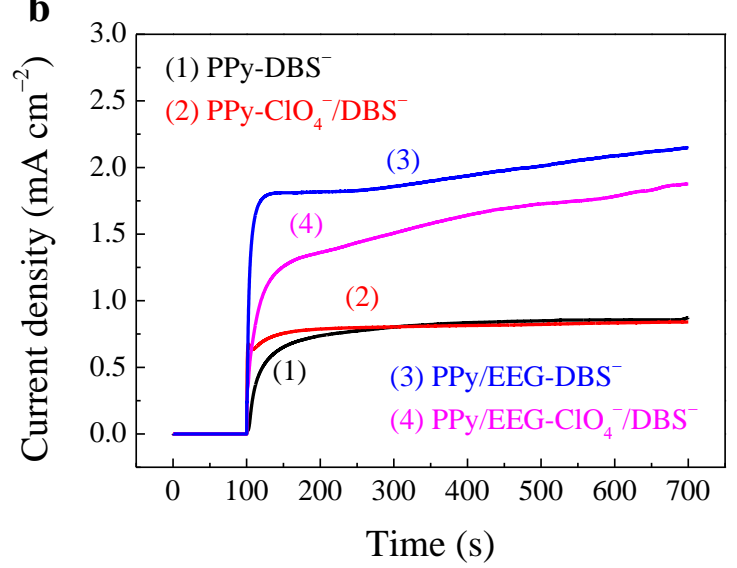

d

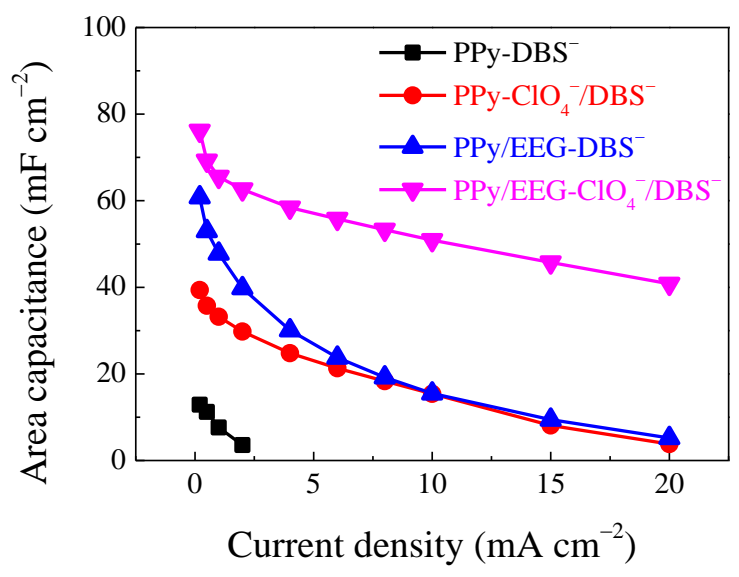

Figure 2. The effect of the precursor electrolyte formulation on the electrodeposition and performance of the PPy/EEG composite electrodes. (a) Photographs of the EEG aqueous dispersions (2 $\mathrm{mg} \mathrm{mL}^{-1}$ ) with and without SDBS. (b) Chronoamperometric curves recorded during the electrodeposition of PPy and PPy/EEG composite electrodes (the concentration of EEG in the precursor solution is $0.1 \mathrm{mg} \mathrm{mL}^{-1}$ ). (c) CVs of the PPy based electrodes at a scan rate of $50 \mathrm{mV} \mathrm{s}^{-1}$, recorded in $1 \mathrm{M} \mathrm{KCl}$ aqueous electrolyte. (d) Rate capability of PPy based electrodes. 
Table 1. Formulations of the precursor electrolyte solutions for the electrodeposition of carbon and PPy composite electrodes.

\begin{tabular}{|c|c|c|c|c|}
\hline \multirow[b]{2}{*}{ Sample } & \multicolumn{4}{|c|}{ Concentration } \\
\hline & $\begin{array}{c}\mathrm{LiClO}_{4} \\
(\mathrm{mM}) \\
\end{array}$ & $\begin{array}{l}\text { Pyrrole } \\
(\mathrm{mM})\end{array}$ & $\begin{array}{r}\text { SDBS } \\
(\mathrm{mM}) \\
\end{array}$ & $\begin{array}{c}\text { Carbon } \\
\left(\mathrm{mg} \mathrm{mL}^{-1}\right)\end{array}$ \\
\hline $\mathrm{PPy}$ or $\mathrm{PPy}-\mathrm{ClO}_{4}^{-} / \mathrm{DBS}^{-}$ & 20 & 72 & $1.43\left(0.5 \mathrm{mg} \mathrm{mL}^{-1}\right)$ & N/A \\
\hline PPy-DBS $^{-}$ & N/A & 72 & 21.43 & N/A \\
\hline PPy/EEG-DBS ${ }^{-}$ & N/A & 72 & 21.43 & 0.1 \\
\hline PPy/EEG-ClO ${ }_{4}^{-} / \mathrm{DBS}^{-}$ & 20 & 72 & 1.43 & 0.1 \\
\hline PPy/CB & 20 & 72 & 1.43 & 0.1 \\
\hline $\mathrm{PPy} / \mathrm{CNTs}$ & 20 & 72 & 1.43 & 0.1 \\
\hline PPy/EEG-0.05 & 20 & 72 & 1.43 & 0.05 \\
\hline PPy/EEG-0.1 & 20 & 72 & 1.43 & 0.1 \\
\hline PPy/EEG-0.2 & 20 & 72 & 1.43 & 0.2 \\
\hline PPy/EEG-0.5 & 20 & 72 & 1.43 & 0.5 \\
\hline
\end{tabular}

It is known that SDBS itself could also act as supporting electrolyte as well as counter anion for the electrochemical polymerization and doping of PPy. ${ }^{15,19}$ As shown in Figure $2 b$, by replacing the $20 \mathrm{mM} \mathrm{LiClO}_{4}$ with $20 \mathrm{mM} \mathrm{SDBS}$ in the precursor solution (total concentration of SDBS $21.43 \mathrm{mM}$ ), the chronoamperometric response of $\mathrm{PPy}_{-} \mathrm{DBS}^{-}$and $\mathrm{PPy}_{-} \mathrm{ClO}_{4}{ }^{-} / \mathrm{DBS}^{-}$ show similar current densities, confirming the role of SDBS as both supporting electrolyte and dopant. In addition, the current density seen in the chronoamperometry for the deposition of PPy/EEG-DBS ${ }^{-}$(21.43 $\left.\mathrm{mM} \mathrm{SDBS}+0.1 \mathrm{mg} \mathrm{mL}^{-1} \mathrm{EEG}\right)$ is larger than that of the PPy/EEG-ClO ${ }_{4}^{-} / \mathrm{DBS}^{-}\left(20 \mathrm{mM} \mathrm{LiClO}_{4}+0.5 \mathrm{mg} \mathrm{mL}^{-1} \mathrm{SDBS}+0.1 \mathrm{mg} \mathrm{mL}^{-1}\right.$ EEG). This is probably due to the better dispersion of EEG with higher concentration of SDBS, which can thus provide more nucleation sites for the polymerization of pyrrole. In addition, similar to oxygen functionalized CNTs and GO, ${ }^{12-13,17}$ the charged EEG itself (probably more negatively charged with higher concentration of surfactant) could also act as weak supporting electrolyte 
for the electrochemical polymerization process.

Nevertheless, the use of SDBS as supporting electrolyte and dopant in the precursor solution compromises the electrochemical performance of the as-deposited electrodes. As shown in Figure $2 \mathrm{c}$, the enclosed area of the cyclic voltammogram $(\mathrm{CV})$ and thus total stored charge for the as-deposited electrodes (see Table 1 for the sample labeling), in order of increasing values is: $\mathrm{PPy}_{-\mathrm{DBS}}{ }^{-}, \mathrm{PPy}_{-} \mathrm{ClO}_{4}{ }^{-} / \mathrm{DBS}^{-}, \mathrm{PPy} / \mathrm{EEG}^{-\mathrm{DBS}^{-}}$and $\mathrm{PPy} / \mathrm{EEG}^{-\mathrm{ClO}_{4}}{ }^{-} / \mathrm{DBS}^{-}$. In addition, the $\mathrm{PPy} / \mathrm{EEG}-\mathrm{ClO}_{4}{ }^{-} / \mathrm{DBS}^{-}$electrode shows a quasi-rectangular characteristic with a pair of nearly symmetric redox peaks located around $-0.1 \mathrm{~V} v s$. SCE, corresponding to the insertion and de-insertion of anions $\left(\mathrm{Cl}^{-}\right)$to the polymer chains. ${ }^{34}$ These results indicate the electrodes formed with SDBS as supporting electrolyte and dopant store fewer charges than the ones with $\mathrm{LiClO}_{4}$. Because of its size, $\mathrm{DBS}^{-}$doped in the PPy polymer chain during the electrochemical polymerization process cannot be readily de-inserted and exchanged with small anions and thus is less efficient for the charge storage via the insertion and de-insertion of anions $\left(\mathrm{Cl}^{-}\right)$in the electrolyte. ${ }^{15,34-35}$ In contrast, for the PPy electrode deposited with $\mathrm{LiClO}_{4}$ as supporting electrolyte, the $\mathrm{ClO}_{4}{ }^{-}$anion can be easily de-inserted during negative polarization, and then exchanged with $\mathrm{Cl}^{-}$, leading to better charge storage ability.

The specific capacitance and rate performance obtained from galvanostatic charge-discharge measurements are consistent with the $\mathrm{CV}$ results. According to Figure $2 \mathrm{~d}$, the areal capacitance of the electrode PPy-DBS ${ }^{-}$shows the smallest value of $<20 \mathrm{mF} \mathrm{cm}^{-2}$, and dropped rapidly at 
higher charge-discharge current densities. In contrast, the $\mathrm{PPy}_{-} \mathrm{ClO}_{4}{ }^{-} / \mathrm{DBS}^{-}$electrode exhibits significantly higher areal capacitance $\left(\sim 40 \mathrm{mF} \mathrm{cm}^{-2}\right)$ with a superior rate capability. This confirms that the PPy deposited in precursor solution with the significantly high concentration of $\mathrm{ClO}_{4}{ }^{-}$ions $(20 \mathrm{mM})$ compared to $\mathrm{DBS}^{-}$ions $(1.43 \mathrm{mM})$ is predominantly doped with the smaller and more mobile $\mathrm{ClO}_{4}{ }^{-}$anions. In addition to the effect of anion dopant size, the difference in the performance of the $\mathrm{PPy}_{-} \mathrm{ClO}_{4}{ }^{-} / \mathrm{DBS}^{-}$and $\mathrm{PPy}_{-} \mathrm{DBS}^{-}$electrodes is also affected by the electrode surface morphology (Figure S1a and b); the PPy-DBS ${ }^{-}$shows a denser and more compact surface than that of the $\mathrm{PPy}_{-} \mathrm{ClO}_{4}{ }^{-} / \mathrm{DBS}^{-}$electrode. This dense and compact surface morphology impedes both the infiltration of electrolyte and the diffusion of ions through the thickness direction of the film electrode.

As shown in Figure 2d, with the addition of EEG, the areal capacitances for both the PPy/EEG-DBS ${ }^{-}$and PPy/EEG-ClO ${ }_{4}^{-} / \mathrm{DBS}^{-}$electrodes show obvious enhancement when compared with the PPy-DBS ${ }^{-}$and $\mathrm{PPy}_{-} \mathrm{ClO}_{4}{ }^{-} / \mathrm{DBS}^{-}$electrodes, respectively. This increase is partially due to the increased loading mass as evidenced by the higher current density during the electrode deposition process (Figure $2 \mathrm{~b}$ ). Meanwhile, the PPy/EEG-ClO ${ }_{4}{ }^{-} / \mathrm{DBS}^{-}$electrode shows higher areal capacitance together with significantly enhanced rate capability than that of the PPy/EEG-DBS ${ }^{-}$electrode, in spite of the lower current density for PPy/EEG-ClO ${ }_{4}^{-} / \mathrm{DBS}^{-}$ electrode during the electrodeposition process (corresponding to a smaller mass loading). Based upon the results of the pure PPy electrodes discussed above, this poor rate performance of the PPy/EEG-DBS ${ }^{-}$electrode is mainly due to the poor mobility of $\mathrm{DBS}^{-}$anion in the bulk 
polymer, which inhibits the doping and de-doping of PPy by smaller anions $\left(\mathrm{Cl}^{-}\right)$in the electrolyte.

In addition, the incorporation of EEG into the electrodes changed the surface morphology of the electrodes (Figure S1c and d). For the PPy/EEG-DBS ${ }^{-}$, the electrode surface is covered by large blocks of polymer $(\sim 10 \mu \mathrm{m}$ in size), which is also responsible for the poor rate performance of the electrode. In contrast, the PPy/EEG-ClO ${ }_{4}^{-} / \mathrm{DBS}^{-}$electrode shows a much finer surface morphology. Since the PPy/EEG-ClO ${ }_{4}^{-} / \mathrm{DBS}^{-}$electrode shows the highest areal

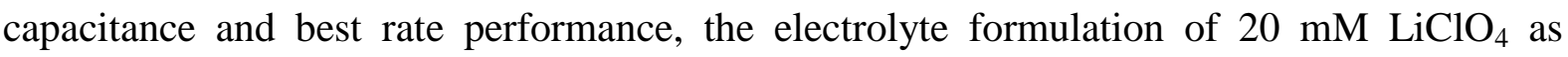
supporting electrolyte with $0.5 \mathrm{mg} \mathrm{mL} \mathrm{mL}^{-1} \mathrm{SDBS}$ as surfactant has been selected for the electrodeposition of PPy/CB and PPy/CNTs composites.

As shown in Figure $3 \mathrm{a}$ and b, the as-deposited PPy/CB and PPy/CNTs composite electrodes had a porous surface, which benefitted ion transport into the electrodes. In addition, the surface morphologies revealed with higher magnification SEM in Figure 3a and b (insets) display the particulate and tubular morphologies of the $\mathrm{CB}$ and CNTs, respectively. Electrochemical measurements show superior performance for both the PPy/CB and PPy/CNTs composite electrodes, compared to the $\mathrm{PPy}-\mathrm{ClO}_{4}{ }^{-} / \mathrm{DBS}^{-}$electrode. The $\mathrm{CVs}$ (Figure $3 \mathrm{c}$ and d) for both the $\mathrm{PPy} / \mathrm{CB}$ and PPy/CNTs show an increased enclosed area compared to the $\mathrm{PPy}-\mathrm{ClO}_{4}{ }^{-} / \mathrm{DBS}^{-}$ electrode with clear anion doping peak at around $0.1 \mathrm{~V} v$ s. SCE. As a result, the PPy/CB and $\mathrm{PPy} / \mathrm{CNTs}$ composite electrodes exhibit nearly twice the areal capacitance $\left(\sim 80 \mathrm{mF} \mathrm{cm}{ }^{-2}\right)$ of 
the $\mathrm{PPy}-\mathrm{ClO}_{4}{ }^{-} / \mathrm{DBS}^{-}$electrode $\left(\sim 40 \mathrm{mF} \mathrm{cm}^{-2}\right)$, together with significantly enhanced rate capability (Figure 3e and f).
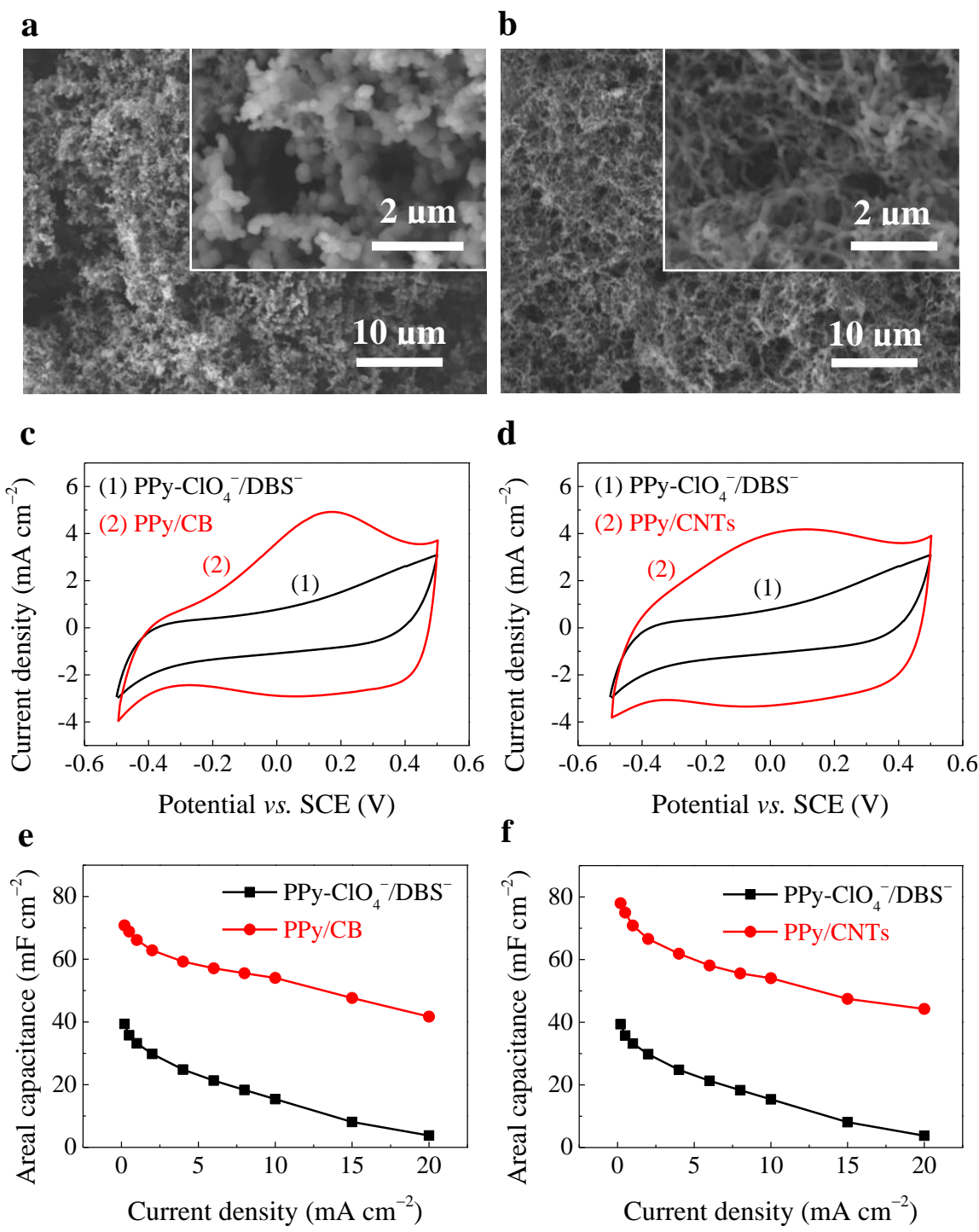

Figure 3. Surface morphology and electrochemical performance of the PPy/CB and PPy/CNTs composite electrodes. (a) and (b) SEM surface morphologies of the PPy/CB and PPy/CNTs composite electrode, respectively. The insets are SEM images with higher magnification. (c) and (d) CVs of the PPy/CB and PPy/CNTs composite electrode, respectively. (e) and (f) Rate capability of the PPy/CB and PPy/CNTs composite electrodes, respectively.

These results for the electrodeposited PPy/CB, PPy/CNTs and PPy/EEG composite electrodes 
successfully demonstrate the versatility of the quaternary electrolyte formulation in fabricating pristine carbon nanomaterial and conducting polymer composite electrodes. Although the EEG is slightly oxidized during the electrochemical exfoliation process, it is not readily dispersible in aqueous media, particularly in the presence of salt $\left(\mathrm{LiClO}_{4}\right)$. In addition, the CNTs and CB are used as-received without any chemical or electrochemical process to introduce functionalities. Hence, it is reasonable to conclude that the quaternary electrolyte formulation is suitable for the electrodeposition of pristine, un-functionalized carbon and PPy composites.

To further explore the effect of carbon concentration in the precursor solution on the morphology and performance of the as-deposited composite electrodes, EEG has been taken as an example for further experiments. Figure 4a shows the chronoamperometric curves recorded during the electrodeposition of PPy/EEG composites with different EEG concentrations in the precursor solution. It is clear that the deposition current density increases with increasing EEG concentration. With reference to the previous reports about electrodeposition of graphene oxide and PPy composites, ${ }^{12}$ the increased EEG concentration could provide more sites for the nucleation and growth of PPy, resulting in larger deposition current density. Meanwhile, the EEG itself could act as weak supporting electrolyte which also accelerates the deposition of PPy. TGA analysis in argon atmosphere has been used to estimate the composition of the as-prepared PPy/EEG composites. As shown in Figure 4b, the weight losses of EEG (12.43\%) and PPy $(31.77 \%)$ at $500{ }^{\circ} \mathrm{C}$ are distinctly different; hence it is possible to calculate the approximate content of EEG in each PPy/EEG composite. As a result, the estimated weight 
compositions of EEG in the PPy/EEG-0.1, PPy/EEG-0.2 and PPy/EEG-0.5 composites are $14.5 \%, 26.6 \%$ and $47.3 \%$, respectively. The increased content of EEG in the composites has been further revealed by the SEM surface morphology. As shown in Figure 4d, f, g and h, the proportion of area covered by the flaky PPy coated EEG flakes increases with the rise of EEG concentration from 0.05 to $0.5 \mathrm{mg} \mathrm{mL}^{-1}$. For the PPy/EEG-0.5 electrode, nearly the whole electrode surface is covered by the interconnected PPy coated EEG flakes.

The addition of EEG in the precursor solution also affects the size of the as-grown PPy particles. As shown in Figure 4c (inset) and e, the particle size of the as-grown PPy without addition of EEG is approximately 1 to $2 \mu \mathrm{m}$ in diameter, while the size for the PPy particles in the PPy/EEG composites is generally smaller than $1 \mu \mathrm{m}$. The difference could be explained by the change of nucleation and growth mechanism via addition of EEG. According to the SEM images of the EEG flakes (Figure S2), there is certain amount of small debris (flake size < 1 $\mu \mathrm{m})$. These small debris could act as preferential sites for the nucleation and growth of PPy particles, leading the smaller particle size than the pure PPy case. In addition, due to the electrophoretic mobility of charged particles is inversely proportional to the particle radius, ${ }^{36-37}$ the small debris moves faster towards the electrode surface compared to the large EEG flakes, This results in the unique morphology of large interconnected PPy coated EEG flakes decorated on the top of a bottom layer made of smaller PPy particles (Figure 4d, f, $g$ and $h$ ). 

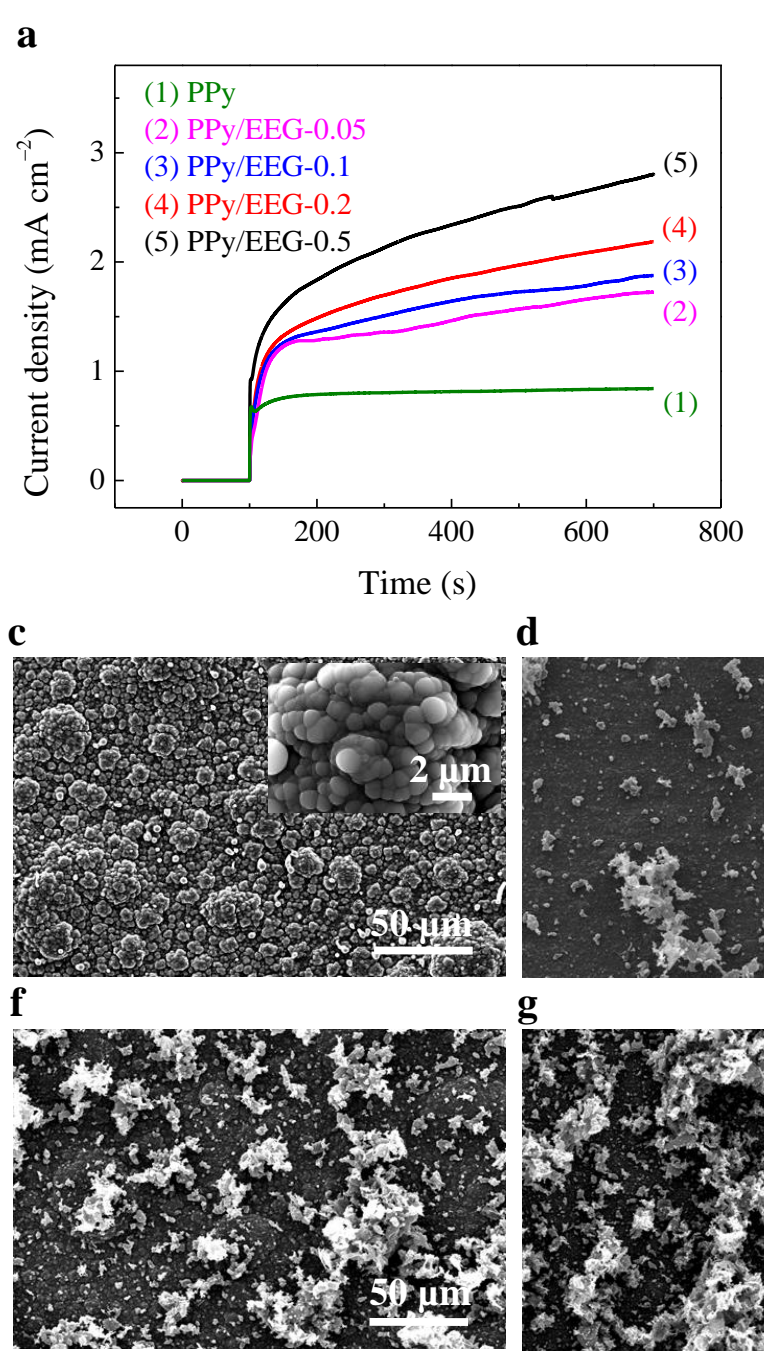

d
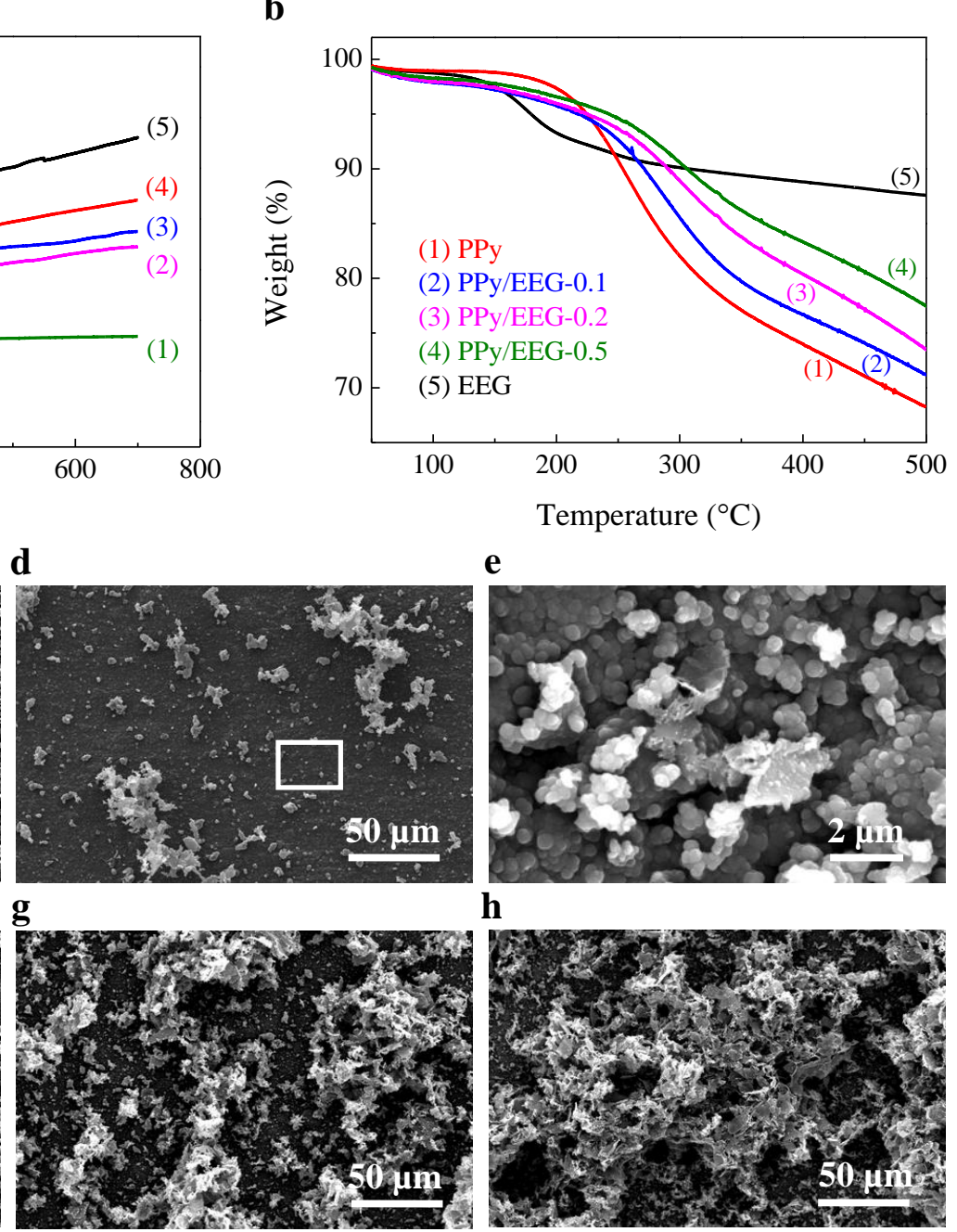

$\mathbf{e}$
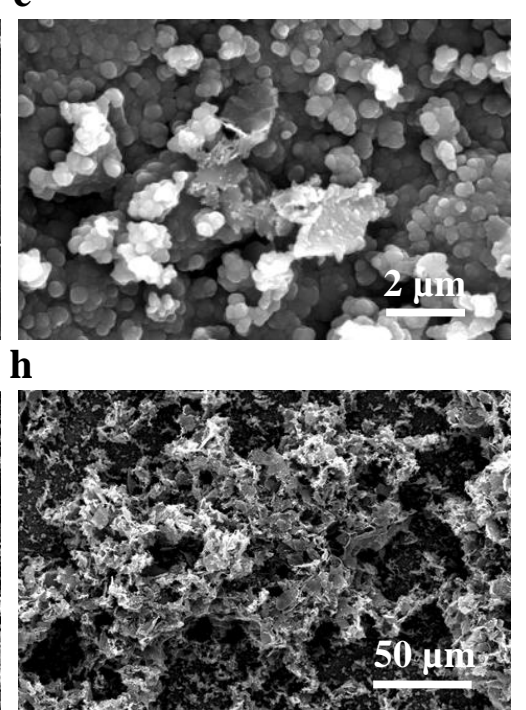

Figure 4. Effect of EEG concentration in the precursor solution on the composition and morphology of the PPy/EEG composites. (a) Chronoamperometry recorded during the electrodeposition of PPy/EEG composites. (b) TGA of the EEG, pure PPy and PPy/EEG composites. (c) SEM image of the PPy electrode, the inset is at higher magnification. (d) SEM surface morphology of the PPy/EEG-0.05 electrodes. (e) Enlarged SEM image for the area marked by the white square in (d). (f), (g) and (h) SEM surface morphologies of the PPy/EEG-0.1, PPy/EEG-0.2 and PPy/EEG-0.5 electrodes, respectively.

The surface and cross-sectional SEM images (Figure 5a and b) with higher magnification for PPy/EEG-0.5 composite electrode show clearly that the top layer is made of interconnected flakes of PPy coated EEG with large flake size up to $10 \mu \mathrm{m}$. From the cross-sectional view 
(Figure 5b), it is easy to distinguish the bottom layer of PPy (marked by white arrow) and the top layer of PPy coated EEG flakes. This unique morphology could assure a good electrical contact between the composite film and the Ti foil current collector via the uniform bottom layer, while the top porous layer could allow fast electrolyte penetration and ion diffusion through the thickness direction of the film. TEM images (Figure 5c and d) of the PPy/EEG-0.5 composite confirm that the EEG flake is uniformly coated with PPy.

The specific surface area and pore size distribution have been derived from the nitrogen adsorption/desorption isotherms (Figure S3). The results indicate that the PPy, EEG and PPy/EEG-0.5 composites have specific surface areas of $4.13,11.13$ and $16.48 \mathrm{~m}^{2} \mathrm{~g}^{-1}$, respectively, with similar pore size distributions. Although the PPy/EEG-0.5 composite exhibits increased specific surface area than that of PPy and EEG due to the formation of porous structure, the specific surface area of $16.48 \mathrm{~m}^{2} \mathrm{~g}^{-1}$ is much smaller than that of activated carbons. This is due to the macro-pores formed by the interconnection of EEG flakes being generally large in size (micrometer scale), and thus contributing much less to the specific surface area compared with micropores $(<2 \mathrm{~nm})$ and mesopores $(2$ to $50 \mathrm{~nm})$. Nevertheless, the pseudo-capacitive charge-storage mechanism of PPy is based on the anion insertion and de-insertion into the bulk polymer chains, and thus less dependent on the specific surface area compared with the double-layer charge-storage mechanism of porous carbon materials. 
$\mathbf{a}$

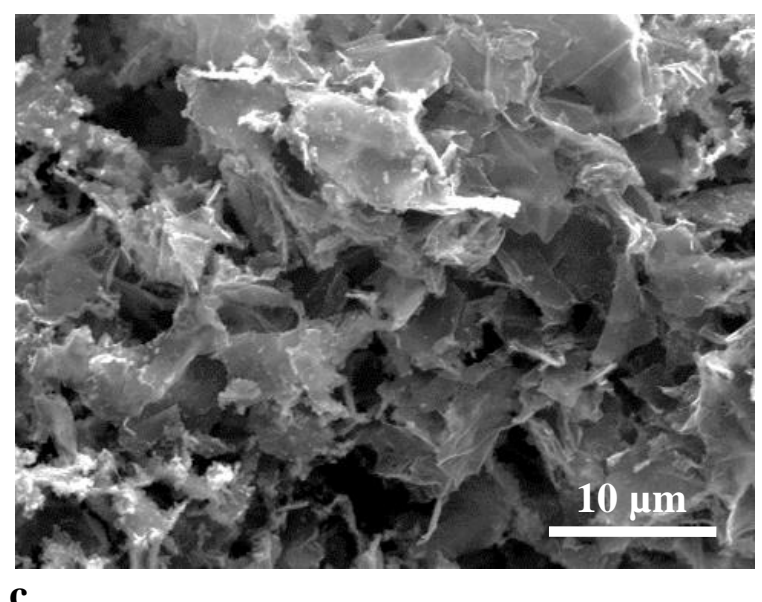

c

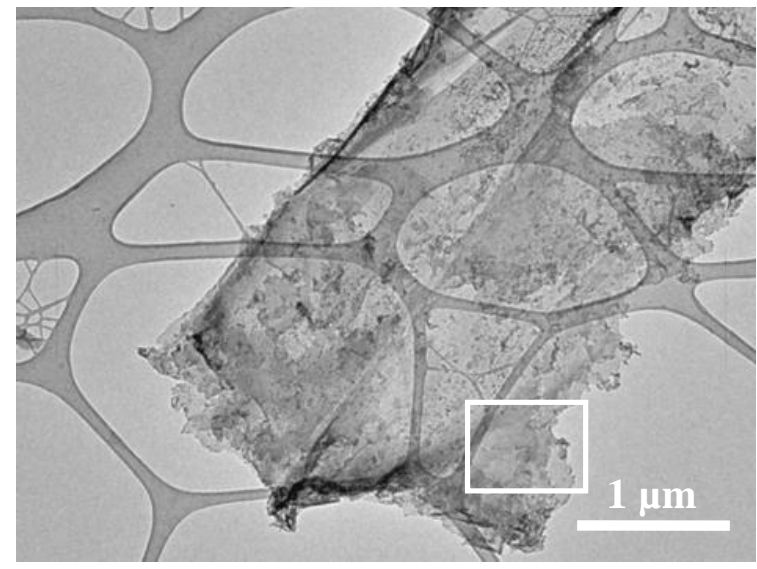

b

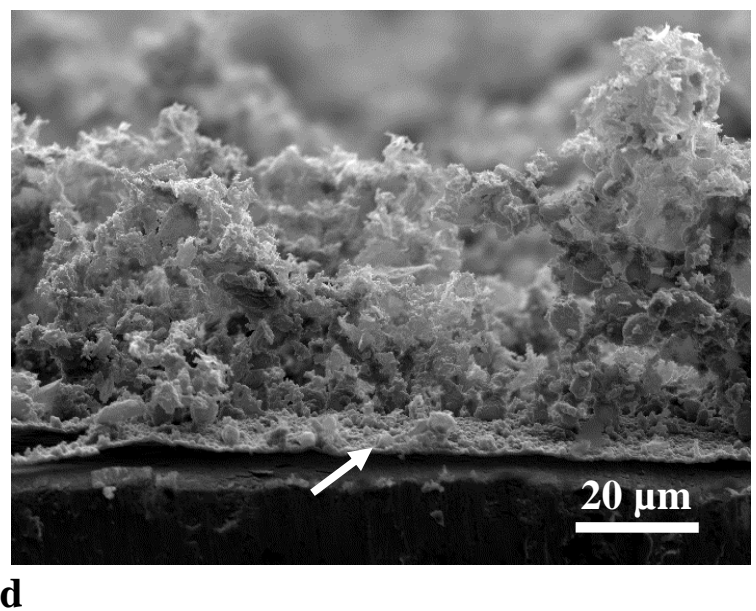

d

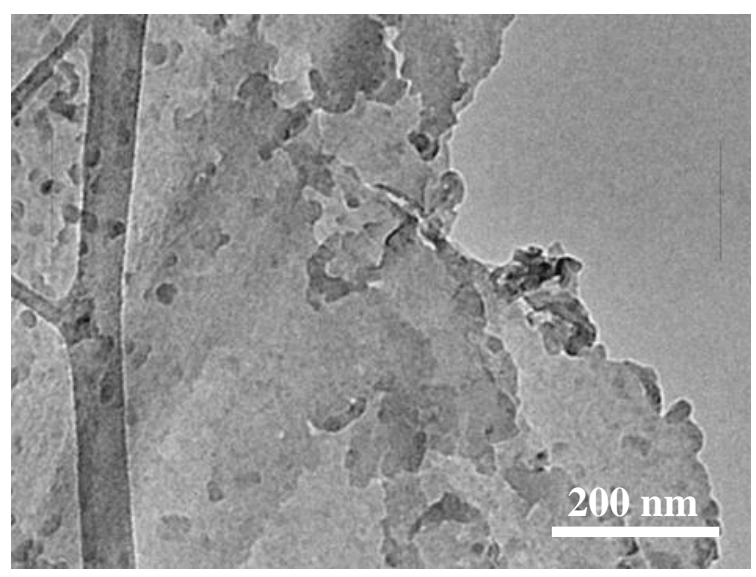

Figure 5. Electron microscopy characterization of the PPy/EEG-0.5 composite. (a) SEM of the PPy/EEG-0.5 composite electrode. (b) SEM of a cross-section of the the PPy/EEG-0.5 composite electrode. (c) and (d) TEM images of PPy/EEG-0.5 composite, (d) is the enlarged area marked by the white square in (c).

FT-IR spectroscopy was used to characterize the functionalities of the as-prepared PPy/EEG composites. For reference, the FT-IR spectra of EEG and pure PPy are also recorded and analyzed. As shown in Figure 6a, the spectrum of EEG shows the characteristics of oxygen groups which are formed during the anodic electrochemical exfoliation process; the vibration of $\mathrm{O}-\mathrm{H}$ and $\mathrm{C}-\mathrm{O}$ groups at 1387 and $1049 \mathrm{~cm}^{-1}$, respectively. ${ }^{38}$ The band located at around $1550 \mathrm{~cm}^{-1}$ can be assigned to the stretching of $\mathrm{C}-\mathrm{C}$ bonds, and the band at $1655 \mathrm{~cm}^{-1}$ is due to 
the deformation vibration of adsorbed water molecules. ${ }^{28,30,38}$ For PPy, the bands at 1550 and $1038 \mathrm{~cm}^{-1}$ correspond to the stretching vibration of $\mathrm{C}-\mathrm{C}$ and deformation vibration of $\mathrm{C}-\mathrm{H}$, respectively. ${ }^{12}$ The bands at 1457 and $1305 \mathrm{~cm}^{-1}$ are related to the stretching vibration of $\mathrm{C}-\mathrm{N}$ bond in the pyrrole ring. ${ }^{12,39}$ Furthermore, the bands at 963 and $770 \mathrm{~cm}^{-1}$ suggest that the pyrrole is polymerized, and the bands at 1187 and $905 \mathrm{~cm}^{-1}$ confirm that the PPy is in a doped state. ${ }^{39}$ The bands at around 1384 and $1740 \mathrm{~cm}^{-1}$ are associated with the $\mathrm{C}-\mathrm{O}$ and $\mathrm{C}=\mathrm{O}$ groups formed by over-oxidation during the electrochemical polymerization of pyrrole. ${ }^{10,12}$ The FT-IR spectrum of PPy/EEG inherits all the characteristics of the PPy spectrum, confirming the formation of PPy/EEG composite. In addition, the slightly down shifted band for the $\mathrm{C}-\mathrm{C}$ stretching vibration of the pyrrole ring, from 1558 to $1553 \mathrm{~cm}^{-1}$, reflects $\pi-\pi$ interaction between the pyrrole ring of PPy and the conjugated domain of EEG. ${ }^{12,40}$ 
$\mathbf{a}$
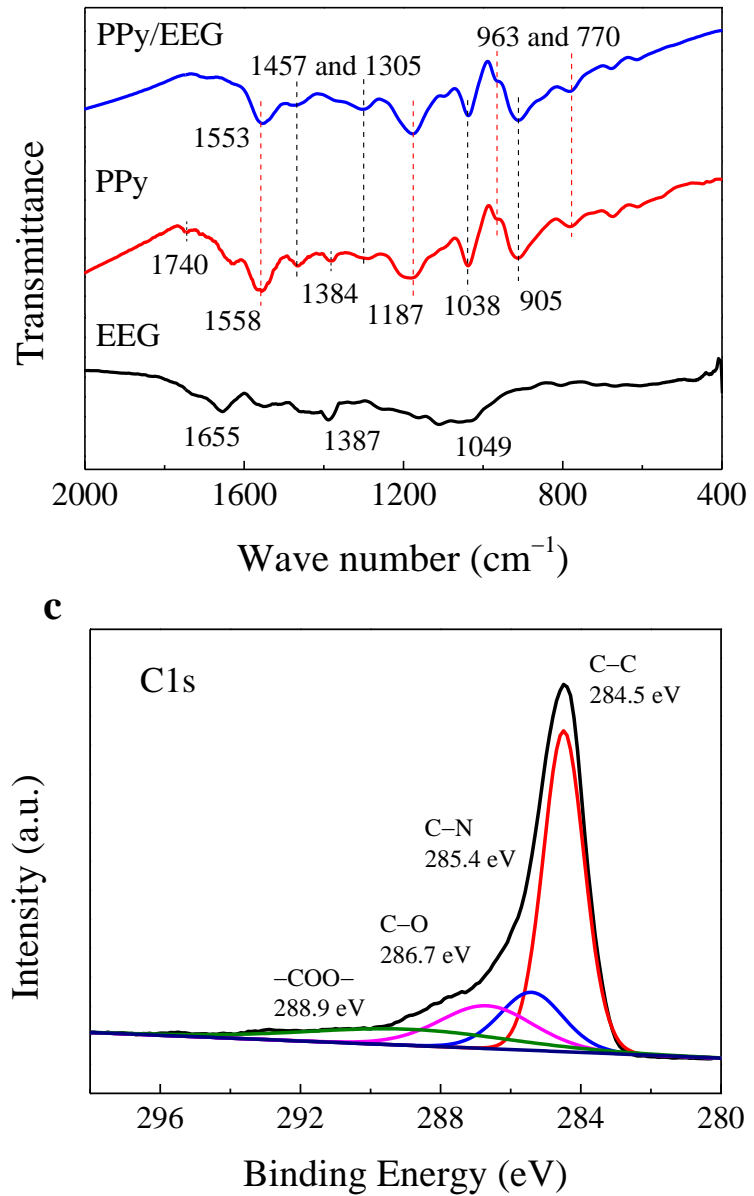

b

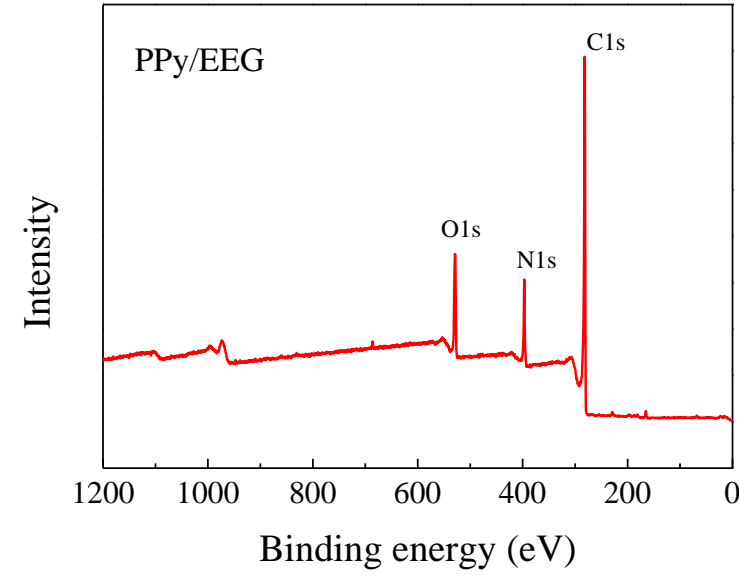

d

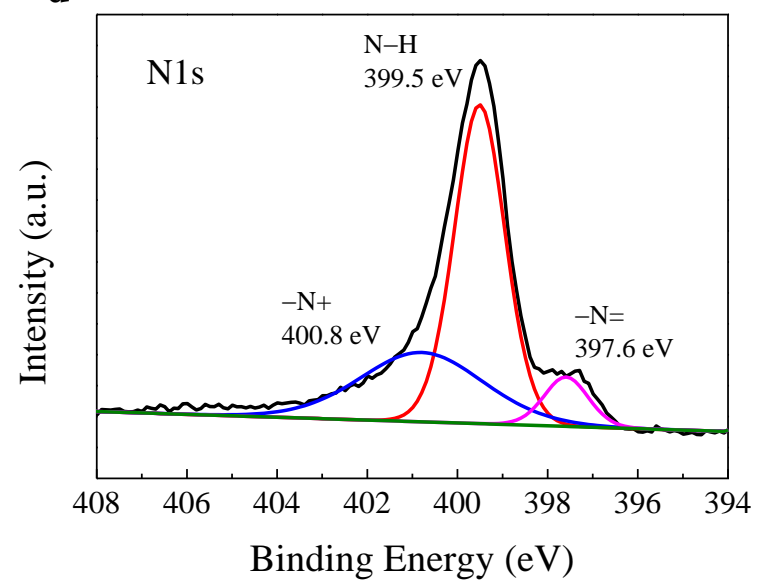

Figure 6. FT-IR and XPS characterizations of the PPy/EEG composite. (a) FT-IR spectra of EEG, PPy and PPy/EEG-0.5 composite. (b) XPS survey spectrum of the PPy/EEG-0.5 composite. (c) and (d) C1s and N1s spectra of the PPy/EEG-0.5 composite, respectively.

The elemental composition and chemical state of each element for the PPy/EEG composite have been further investigated by XPS. According to the survey spectrum (Figure 6b), the PPy/EEG-0.5 composite is mainly composed of carbon, nitrogen and oxygen elements. The deconvolution of $\mathrm{C} 1 \mathrm{~s}$ spectrum (Figure 6c) results in four components: $\mathrm{C}-\mathrm{C}$ at $284.5 \mathrm{eV}, \mathrm{C}-\mathrm{N}$ at $285.4 \mathrm{eV}, \mathrm{C}-\mathrm{O}$ at $286.7 \mathrm{eV}$ and $-\mathrm{COO}-$ at $288.9 \mathrm{eV}^{12}$ The existence of oxygen functionalities is in consistent with the FT-IR results. According to Figure 6d, the N1s spectrum 
can be deconvoluted into three components. The dominant peak centred at $399.5 \mathrm{eV}$ is corresponding to the neutral amine nitrogen $(\mathrm{N}-\mathrm{H})$, the component at higher binding energy of $400.8 \mathrm{eV}$ can be assigned to the positively charged nitrogen $\left(-\mathrm{N}^{+}\right)$, and the one with lower binding energy of $397.6 \mathrm{eV}$ is related to the imine nitrogen $(-\mathrm{N}=) .{ }^{12,15,41}$ Moreover, the ratio of $-\mathrm{N}^{+} / \mathrm{N}$ can be used to quantify the doping level of PPy. ${ }^{15,41}$ Hence, a doping level of 0.32 is obtained from the $-\mathrm{N}^{+} / \mathrm{N}$ ratio, which is close to the theoretical value 0.33 (three monomers per dopant) for PPy. ${ }^{1}$

A three-electrode configuration with a Pt mesh counter electrode and a SCE reference electrode was used to investigate the electrochemical performance of single electrodes. Figure 7a shows the CVs recorded at $50 \mathrm{mV} \mathrm{s}^{-1}$ for the PPy/EEG composite electrodes deposited in the precursor solutions with different EEG concentrations from 0.05 to $0.5 \mathrm{mg} \mathrm{mL}^{-1}$. For comparison, the CV of pure PPy electrode is also displayed. The current density and thus the enclosed area of CV are enhanced with the addition of EEG and rise with the increase of EEG concentration. Moreover, the CVs for the PPy/EEG composites show a more "rectangular" characteristic than the pure PPy electrode, suggesting enhanced electrical and ionic transport in the PPy/EEG composite electrodes. Furthermore, there is a negative shift of the re-doping (anion insertion) peak with the increase of EEG concentration from 0.05 to $0.2 \mathrm{mg} \mathrm{mL}^{-1}$. As discussed above, a higher EEG concentration in the precursor solution leads to an increased EEG composition in the as-formed PPy/EEG composite; and the electrode changes from a compact bottom layer (assembled by PPy particles) dominated morphology to a porous top 
layer (assembled by PPy coated EEG flakes) dominated morphology. The changes in the EEG composition and the electrode morphology could benefit the electronic and ionic transport in the composite electrode, respectively, leading to a fast and efficient electrochemical doping of PPy. The greatly improved electrochemical performance can be further proved by comparing the CVs recorded at various scan rates from 5 to $500 \mathrm{mV} \mathrm{s}^{-1}$ for the PPy/EEG-0.5 composite and the pure PPy electrode (Figure S4).

Galvanostatic charge-discharge measurements of the as-prepared electrodes were consistent with the $\mathrm{CV}$ measurements. The discharge curves $\left(1 \mathrm{~mA} \mathrm{~cm}^{-2}\right)$ for the composite electrodes exhibit a linear shape corresponding to a typical capacitive behaviour (Figure S5). The areal capacitance (in $\mathrm{mF} \mathrm{cm}^{-2}$ ) and the specific capacitance (in $\mathrm{F} \mathrm{g}^{-1}$ ) of the electrode obtained from the galvanostatic charge-discharge measurements at various current densities are displayed in Figure $7 \mathrm{~b}$ and c, respectively. Summary of the mass loadings, areal and specific capacitances, as well as capacitance retentions at high rate are available in Table 2. According to Figure 7b, the areal capacitance of the electrode increases with the rise of EEG concentrations in the precursor solution. The enhanced areal capacitance for the PPy/EEG composite electrodes is partly due to the higher mass loadings of the electrodes as shown in Table 2, but also the addition of EEG improves both the electronic and ionic transport in the electrode. 
$\mathbf{a}$

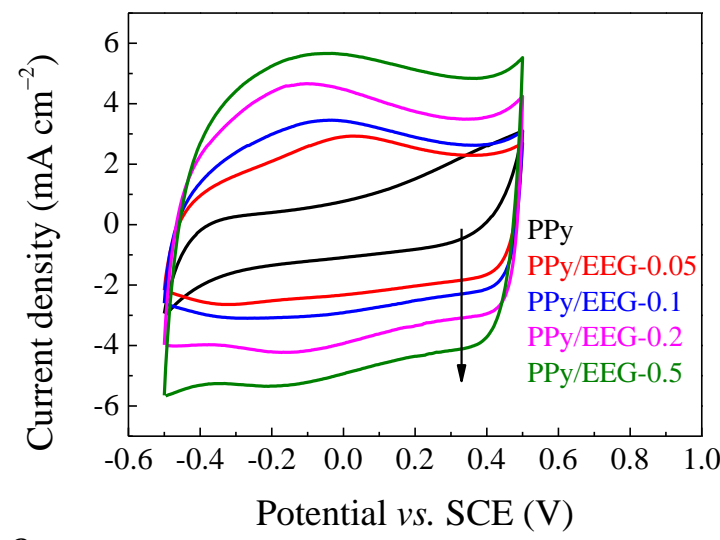

c

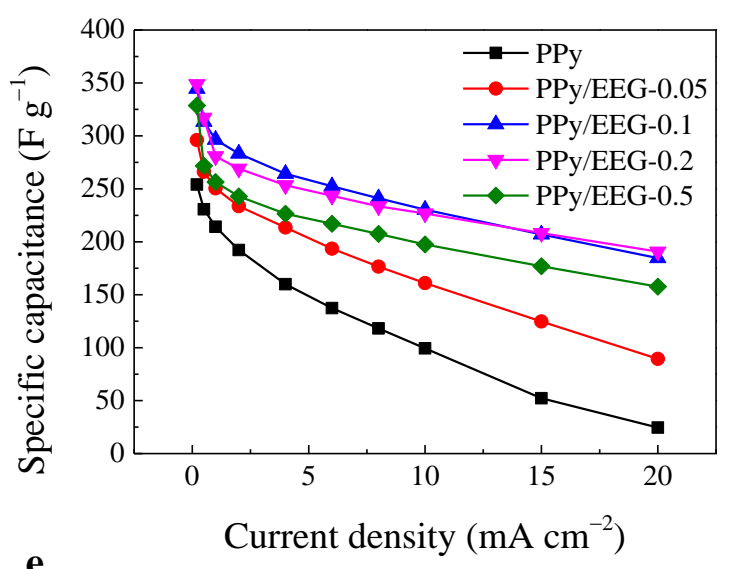

e

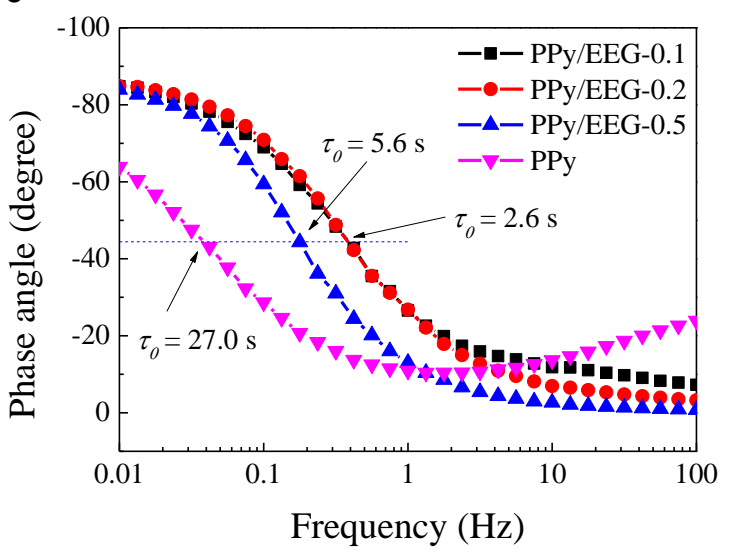

b
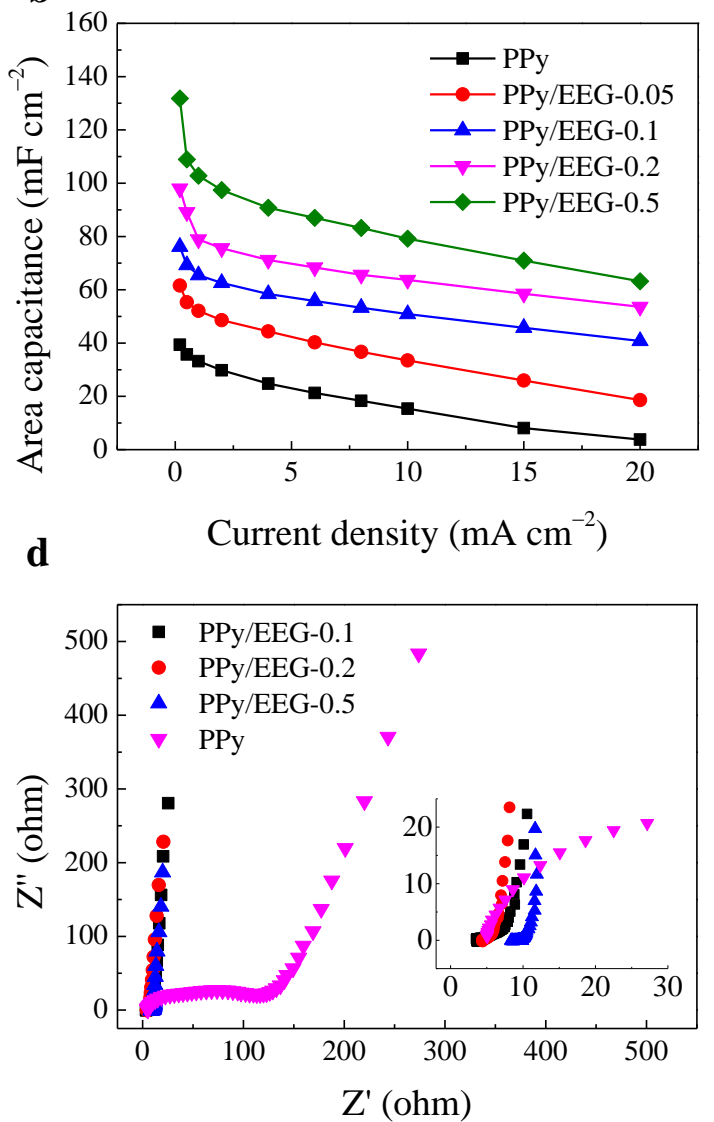

f

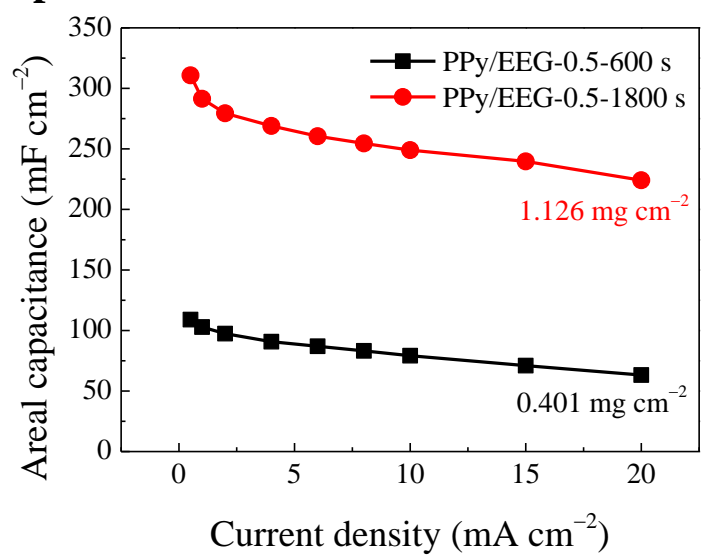

Figure 7. Electrochemical performance of the single electrodes. (a) CVs of the PPy/EEG composite electrodes at a scan rate of $50 \mathrm{mV} \mathrm{s}^{-1}$. (b) Evolution of area capacitance with current density for the PPy/EEG composite electrodes. (c) Evolution of specific capacitance with current density for the PPy/EEG composite electrodes. (d) Nyquist plots of the PPy/EEG composite electrodes. (e) Bode plots of phase angle versus frequency for the PPy/EEG composite electrodes. (f) Evolution of areal capacitances with current density for PPy/EEG-0.5 electrodes with deposition time of 600 and $1800 \mathrm{~s}$. 
Table 2. Summary of the mass loadings, area capacitances, specific capacitances and capacitance retentions for the PPy/EEG composite electrodes with different EEG concentrations in the precursor solution.

\begin{tabular}{|c|c|c|c|c|c|c|}
\hline \multirow{2}{*}{ Sample } & \multirow{2}{*}{$\begin{array}{l}\text { Mass loading } \\
\left(\mathrm{mg} \mathrm{cm}^{-2}\right)\end{array}$} & \multicolumn{2}{|c|}{ Areal capacitance $\left(\mathrm{mF} \mathrm{cm}^{-2}\right)$} & \multicolumn{2}{|c|}{ Specific capacitance $\left(\mathrm{F} \mathrm{g}^{-1}\right)$} & \multirow{2}{*}{$\begin{array}{l}\text { Ret. } \\
(\%)\end{array}$} \\
\hline & & $0.2 \mathrm{~mA} \mathrm{~cm}^{-2}$ & $20 \mathrm{~mA} \mathrm{~cm}^{-2}$ & $0.2 \mathrm{~mA} \mathrm{~cm}^{-2}$ & $20 \mathrm{~mA} \mathrm{~cm}^{-2}$ & \\
\hline PPy & 0.155 & 39.4 & 3.8 & 254.1 & 24.5 & 10 \\
\hline PPy/EEG-0.05 & 0.208 & 61.6 & 18.6 & 296.1 & 89.4 & 30 \\
\hline PPy/EEG-0.1 & 0.221 & 76.2 & 40.8 & 344.6 & 184.6 & 53 \\
\hline PPy/EEG-0.2 & 0.281 & 98.0 & 53.6 & 348.8 & 190.7 & 55 \\
\hline PPy/EEG-0.5 & 0.401 & 131.8 & 63.2 & 328.7 & 157.6 & 48 \\
\hline
\end{tabular}

The effect of EEG can be further confirmed by the evolution of specific capacitance with the increase of discharge current density. As shown in Figure 7c and Table 2, the specific capacitance of pure PPy electrode is $254.1 \mathrm{~F} \mathrm{~g}^{-1}$ at $0.2 \mathrm{~mA} \mathrm{~cm}^{-2}$, and then drops rapidly to 24.5 $\mathrm{F} \mathrm{g}^{-1}$ at $20 \mathrm{~mA} \mathrm{~cm}^{-2}$. In contrast, the PPy/EEG-0.2 composite electrode shows a high specific capacitance of $348.8 \mathrm{~F} \mathrm{~g}^{-1}$ at $0.2 \mathrm{~mA} \mathrm{~cm}^{-2}$, and is able to retain at a specific capacitance of 190.7 $\mathrm{F} \mathrm{g}^{-1}$ at the large current density of $20 \mathrm{~mA} \mathrm{~cm}^{-2}\left(71 \mathrm{~A} \mathrm{~g}^{-1}\right)$. The enhancement in both specific capacitance and rate capability of the PPy/EEG composite is closely related to the effect of EEG on the structure and morphology of the as-deposited electrode. As discussed above, the addition of EEG reduces the particle size of PPy in the bottom layer, which could benefit the insertion of anions into the bulk of PPy particle, thus fully utilizing the pseudo-capacitance of PPy. In addition, the top porous layer assembled by the interconnected PPy coated highly conductive EEG flakes is ideal for fast electron and ion transfer. However, with the further increase of EEG concentration to $0.5 \mathrm{mg} \mathrm{mL} \mathrm{m}^{-1}$, even though the areal 
capacitance can be further enhanced to $131.8 \mathrm{mF} \mathrm{cm}^{-2}$ due to the increased mass loading, the specific capacitance drops slightly to $328.7 \mathrm{~F} \mathrm{~g}^{-1}\left(0.5 \mathrm{~mA} \mathrm{~cm}^{-2}\right)$ with a retention of $48 \%$ at 20 $\mathrm{mA} \mathrm{cm}{ }^{-2}$. The slightly deteriorated specific capacitance of PPy/EEG-0.5 composite electrode compared with PPy/EEG-0.2 is due to the increased content of EEG (47.3\%), which cannot provide as large pseudo-capacitance as PPy. A previous report suggests that the specific capacitance of EEG in $6 \mathrm{M} \mathrm{KOH}$ is $59 \mathrm{~F} \mathrm{~g}^{-1} \cdot{ }^{30}$ Meanwhile, the drop of capacitance retention for PPy/EEG-0.5 electrode at $20 \mathrm{~mA} \mathrm{~cm}^{-2}$ (48\%) compared with for PPy/EEG-0.2 electrode (55\%) is probably due to the increased mass loading and thus thickness of the electrode, leading to a relatively larger internal resistance.

Electrochemical impedance spectroscopy (EIS) was used to characterize the resistance and frequency response of the as-prepared composite electrodes. As shown in Figure $7 \mathrm{~d}$ and its inset, the large semicircle appears in the Nyquist plot of pure PPy electrode suggests a significantly larger charge transfer resistance $(>100 \mathrm{ohm})$ than that of the PPy/EEG composite electrodes $(<10 \mathrm{ohm})$. The large charge transfer resistance of pure PPy electrode is due to (1) the compact electrode morphology and large particle size of PPy, leading to poor ion mobility in the electrode and (2) the absence of highly conductive EEG to provide fast electron transfer routes. In contrast, the particle size of the bottom layer in the PPy/EEG composite electrode is significantly reduced compared with that of pure PPy electrode (Figure 4c and e), and the PPy/EEG composite electrodes has a porous top layer made of PPy coated EEG flakes (Figure 5b). These characteristics are favourable for the fast ion movement and insertion into the bulk 
PPy. Hence, combining with the high electrical conductivity of EEG, the PPy/EEG composite electrodes exhibit much smaller equivalent series resistances than that of pure PPy electrode. In addition, the nearly vertical Nyquist plots in the low frequency region for the PPy/EEG composite electrodes suggest an ideally capacitive behaviour. This result is consistent with the deteriorated rate performance of PPy/EEG-0.5 electrode obtained from the galvanostatic charge-discharge measurement. Bode plots of phase angle versus frequency (Figure 7e) suggest that the time constant ( $\tau_{0}$, corresponding to the frequency at the phase angle of $-45^{\circ}$ ) for the PPy/EEG composite electrodes $(<10 \mathrm{~s})$ are significantly shorter than that of the pure PPy electrode (27.0 s), corresponding to the enhanced rate capability of the composite electrodes. $^{42}$

For practical application, electrodes with high mass loadings are more favourable. Electrodes with mass loadings up to $1.126 \mathrm{mg} \mathrm{cm}^{-2}$ have been prepared by simply increasing the electrodeposition time of PPy/EEG-0.5 electrode from 600 to $1800 \mathrm{~s}$. The comparison of the $\mathrm{CVs}$ at $50 \mathrm{mV} \mathrm{s}^{-1}$ (Figure S6a) indicates an much larger current response with the increase of deposition time from 600 to $1800 \mathrm{~s}$ due to the increased mass loading and thus areal capacitance. As shown in Figure 7f, the areal capacitance of PPy/EEG-0.5-1800 s electrode reaches a high value of $310.8 \mathrm{mF} \mathrm{cm}^{-2}$ at a current density of $0.5 \mathrm{~mA} \mathrm{~cm}^{-2}$, and is maintained at $224.1 \mathrm{mF} \mathrm{cm}^{-2}$ at $20 \mathrm{~mA} \mathrm{~cm}^{-2}$. In terms of specific capacitance, the PPy/EEG-1800s electrode exhibits a value of $276.0 \mathrm{~F} \mathrm{~g}^{-1}$ at $0.4 \mathrm{~A} \mathrm{~g}^{-1}$ and $199.0 \mathrm{~F} \mathrm{~g}^{-1}$ at $17.8 \mathrm{~A} \mathrm{~g}^{-1}$ (Figure S6b). In comparison with the literature values of PPy based electrodes, the PPy/EEG-0.5-1800 s 
composite electrode outperforms the PPy hollow fibers (190 $\mathrm{F} \mathrm{g}^{-1}$ at $\left.0.25 \mathrm{~A} \mathrm{~g}^{-1}\right){ }^{43}$ the PPy/carbon quantum dots composite $\left(248.5 \mathrm{mF} \mathrm{cm}^{-2}\right.$ at $\left.0.2 \mathrm{~mA} \mathrm{~cm}^{-2}\right),{ }^{44}$ the PPy/activated carbon composite $\left(178 \mathrm{~F} \mathrm{~g}^{-1}\right.$ at $\left.0.5 \mathrm{~mA} \mathrm{~cm}^{-2}\right),{ }^{45}$ and comparable with the PPy/cellulose carbon aerogel composite at high rate $\left(210 \mathrm{~F} \mathrm{~g}^{-1}\right.$ at $\left.10 \mathrm{Ag}^{-1}\right) .{ }^{46}$ See Table $\mathrm{S} 1$ for detailed comparison.

Herein, both the PPy/EEG-0.5 electrodes with deposition time of 600 and $1800 \mathrm{~s}$ have been selected for the fabrication of aqueous two-electrode supercapacitor devices, labelled as aqueous and aqueous-high loading, respectively. Figure 8 shows the electrochemical performance of the as-assembled supercapacitor with $1 \mathrm{M} \mathrm{KCl}$ aqueous electrolyte. The rectangular CVs at scan rates ranging from 5 to $50 \mathrm{mV} \mathrm{s}^{-1}$ (Figure 8a) indicate a good supercapacitor with ideal capacitive behaviour. In addition, the CVs at high scan rates up to 500 $\mathrm{mV} \mathrm{s}^{-1}$ are able to retain a relatively good rectangular characteristic (Figure 8b), suggesting a high rate capability. The ideal capacitive behaviour of the supercapacitor has been further confirmed by the galvanostatic charge-discharge curves (Figure 8c), which shows a characteristic symmetric triangular shape, even at large charge-discharge current densities (Figure 8d). The evolution of areal capacitance with the increase of discharge current density (Figure 8e) show that the PPy/EEG-0.5-600 s composite electrode has an areal capacitance of $104.7 \mathrm{mF} \mathrm{cm}^{-2}$ at $0.1 \mathrm{~mA} \mathrm{~cm}^{-2}\left(0.25 \mathrm{~A} \mathrm{~g}^{-1}\right)$, with excellent rate capability of $63.1 \mathrm{mF} \mathrm{cm}^{-2}(60 \%$ retention) at $50 \mathrm{~mA} \mathrm{~cm}{ }^{-2}\left(125 \mathrm{~A} \mathrm{~g}^{-1}\right)$. For the aqueous supercapacitor fabricated using electrodes with high mass loadings (PPy/EEG-0.5-1800 s), the calculated electrode areal capacitance is $233.7 \mathrm{mF} \mathrm{cm}^{-2}$ at $0.5 \mathrm{~mA} \mathrm{~cm}^{-2}\left(0.7 \mathrm{~A} \mathrm{~g}^{-1}\right)$ and remains at $105.3 \mathrm{mF} \mathrm{cm}^{-2}(45 \%$ 
retention) at $50 \mathrm{~mA} \mathrm{~cm}^{-2}\left(69 \mathrm{~A} \mathrm{~g}^{-1}\right)$. The as-recorded $\mathrm{CVs}$ and galvanostatic charge-dicharge curves are available in Figure S7.

a

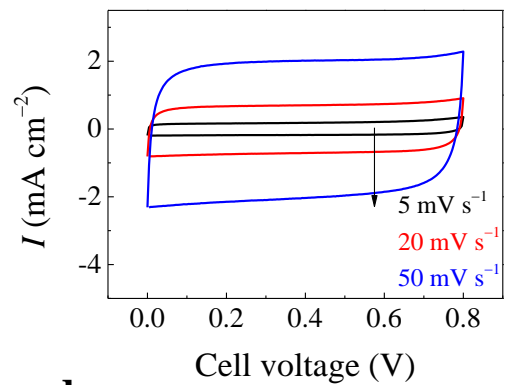

d

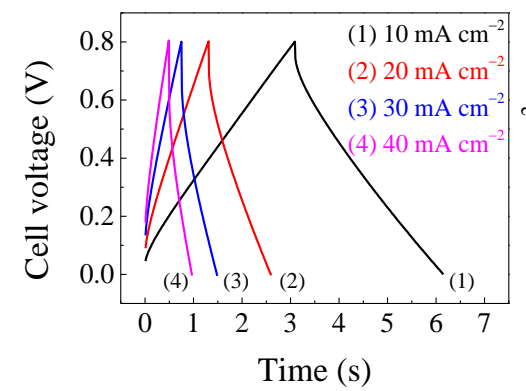

\section{b}

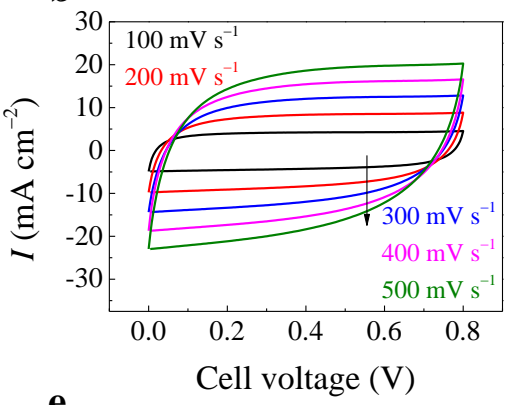

e

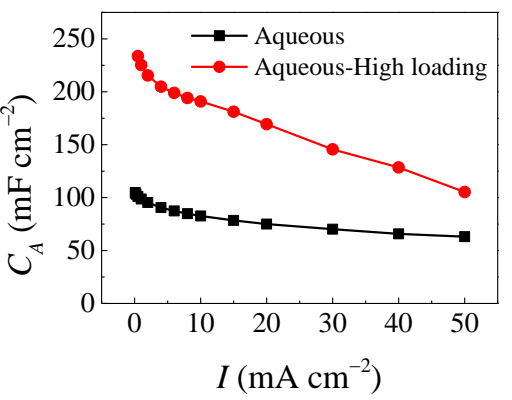

c

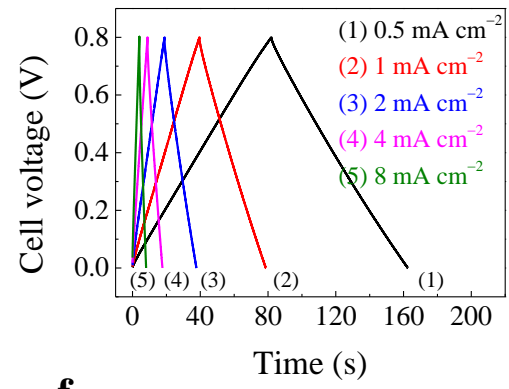

$\mathbf{f}$

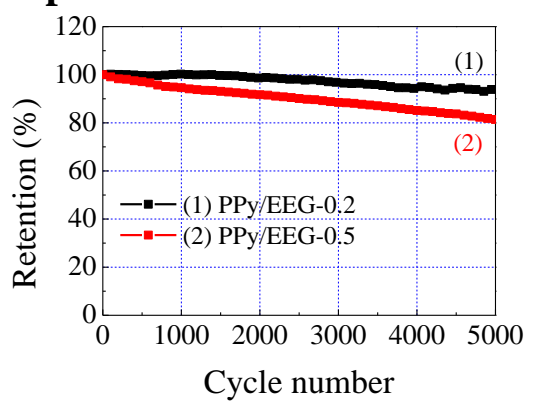

Figure 8. Electrochemical performance of the aqueous supercapacitor based on the PPy/EEG composite electrodes. (a) and (b) CVs at various scan rates. (c) and (d) Galvanostatic charge-discharge curves at various current densities. (e) Evolution of area capacitances with the increase of discharge current density for aqueous and aqueous-high loading devices. (f) Cycling stability measured by galvanostatic charge-discharge at a current density of $6 \mathrm{~mA}$ $\mathrm{cm}^{-2}$.

Cycling stability testing via galvanostatic charge-discharge at a current density of $6 \mathrm{~mA} \mathrm{~cm}^{-2}$ (Figure 8f) shows that the supercapacitor based on PPy/EEG-0.5 composite electrodes can be cycled up to 5000 cycles with capacitance retention of $81.4 \%$. Generally, PPy as a type of conducing polymer, has poor cycling stability due to the volume change caused by anion insertion and de-insertion during cycling. ${ }^{1,11}$ The relatively good cycling stability of PPy/EEG composite electrodes can be possibly attributed to the incorporation of EEG, which provides 
extra mechanical support to PPy thus enhanced mechanical stability during cycling. In addition, the porous top layer made of three-dimensional interconnected PPy coated EEG flakes could act as buffer layer to allow extra space for the volume swelling and shrinkage of PPy during the charge-discharge cycles. However, with the increasing content of EEG flakes in the composite, the connection among the flakes via PPy polymer becomes worse, as revealed by the SEM surface and cross-section morphologies (Figure 4 and 5). This weak connection is not favourable for a stable capacitance under cycling. Hence, an aqueous supercapacitor device based on PPy/EEG-0.2 composite electrodes with lower EEG content (26.6 wt.\%) than PPy/EEG-0.5 (47.3 wt.\%) has been fabricated and tested. As a result, the PPy/EEG-0.2 composite shows high capacitance retention of $93.4 \%$ after 5000 cycles (Figure 8f), which is comparable with reported cycling stability of PPy based electrodes in literatures (Table S1).

To further explore the potential of PPy/EEG composite electrodes, solid-state supercapacitor devices were fabricated using $1 \mathrm{M} \mathrm{LiCl} / \mathrm{PVA}$ gel as the electrolyte. Figure $9 \mathrm{a}$ and b show the as-recorded CVs for the solid-state device at various scan rates up to $500 \mathrm{mV} \mathrm{s}^{-1}$. The typical rectangular shaped $\mathrm{CV}$ s at slow scan rate indicate a well performing supercapacitor, which was further evidenced by the triangular and symmetric galvanostatic charge-discharge curves (Figure 9c). According to Figure 9d, the areal capacitance obtained from the charge-discharge measurement for the solid-state device $\left(88.65 \mathrm{mF} \mathrm{cm}^{-2}\right)$ is smaller than that of the aqueous devices $\left(104.7 \mathrm{mF} \mathrm{cm}^{-2}\right)$ at $0.1 \mathrm{~mA} \mathrm{~cm}^{-2}$, together with a deteriorated rate capability through the increase of discharge current density. The EIS Nyquist plots (Figure 9e) shows an 
equivalent series resistance (ESR) about $4 \mathrm{ohms}$ for the solid-state device, while the value for the aqueous device is around $1 \mathrm{ohm}$. The increased resistance for the solid-state device can be explained by the lower ionic conductivity of the gel polymer electrolyte compared to the aqueous electrolyte. ${ }^{47}$ In addition, as shown in Figure 9e, the ESR of aqueous supercapacitor with high mass loading electrodes remains at a small value of $\sim 2.5$ ohms. Bode plots of phase angle versus frequency (Figure 9f) shows that the time constants for the aqueous, solid-state and aqueous-high loading supercapacitors are $0.29,0.91$, and $1.59 \mathrm{~s}$, respectively, which are significantly smaller than the previously reported device based on GO/PPy composite electrodes $(6.3 \mathrm{~s}) .^{12}$

Ragone plots of energy density versus power density for the aqueous and solid-state devices are displayed in Figure 9g. The aqueous supercapacitor with a cell voltage of $0.8 \mathrm{~V}$ has an energy density of $4.6 \mu \mathrm{Wh} \mathrm{cm}^{-2}$ at $0.04 \mathrm{~mW} \mathrm{~cm}^{-2}$, and able to maintain at $1.3 \mu \mathrm{Wh} \mathrm{cm}^{-2}$ at a

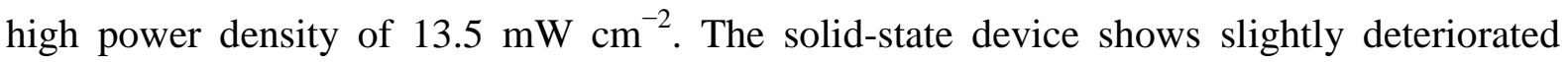
performance with an energy density of $3.9 \mu \mathrm{Wh} \mathrm{cm}^{-2}$ at $0.04 \mathrm{~mW} \mathrm{~cm}^{-2}$ falling to $2.2 \mu \mathrm{Wh} \mathrm{\textrm {cm } ^ { - 2 }}$ at $10.5 \mathrm{~mW} \mathrm{~cm}{ }^{-2}$. The aqueous-high loading supercapacitor has an energy density of $10.1 \mu \mathrm{Wh}$ $\mathrm{cm}^{-2}$ at $0.2 \mathrm{~mW} \mathrm{~cm}^{-2}$, which remains at $2.2 \mu \mathrm{Wh} \mathrm{cm}^{-2}$ at $7.0 \mathrm{~mW} \mathrm{~cm}^{-2}$. The energy density and power density of these supercapacitors based on PPy/EEG composite are better, or comparable to, recent reports on conducting polymer based composites (Figure 9g), especially at high power region with time scale $<3.6 \mathrm{~s}$, including GO/PPy $\left(3.51 \mu \mathrm{Wh} \mathrm{cm}^{-2}\right.$ at $\left.5.76 \mathrm{~mW} \mathrm{~cm}^{-2}\right){ }^{18}$ three-dimensional GO/PPy $\left(13.2 \mu \mathrm{Wh} \mathrm{cm}^{-2}\right.$ at $\left.4 \mathrm{~mW} \mathrm{~cm}^{-2}\right),{ }^{12}$ reduced GO/PPy $\left(10 \mu \mathrm{Wh} \mathrm{cm}^{-2}\right.$ 
at $\left.5 \mathrm{~mW} \mathrm{~cm}{ }^{-2}\right){ }^{19} \mathrm{PPy} / \mathrm{GO} / \mathrm{CNTs}$ ternary composites $\left(1.4 \mu \mathrm{Wh} \mathrm{cm}{ }^{-2}\right.$ at $\left.8.1 \mathrm{~mW} \mathrm{~cm}{ }^{-2}\right){ }^{20}$ poly(3,4-ethylenedioxythiophene)/GO $\left(4.9 \mu \mathrm{Wh} \mathrm{cm}^{-2}\right.$ at $\left.7 \mathrm{~mW} \mathrm{~cm}^{-2}\right),{ }^{48}$ polyaniline/GO $(0.07$ $\mu \mathrm{Wh} \mathrm{cm}^{-2}$ at $\left.0.3 \mathrm{~mW} \mathrm{~cm}^{-2}\right),{ }^{49} \mathrm{PPy} / \mathrm{GO}\left(3.1 \mu \mathrm{Wh} \mathrm{cm}^{-2}\right.$ at $\left.2.1 \mathrm{~mW} \mathrm{~cm}^{-2}\right),{ }^{50}$ and $\mathrm{PPy} / \mathrm{GO} / \mathrm{CNTs}$ $\left(3.8 \mu \mathrm{Wh} \mathrm{cm}^{-2}\right.$ at $\left.2.5 \mathrm{~mW} \mathrm{~cm}^{-2}\right) .{ }^{50}$ Note that the approach demonstrated in the present work applies to a wide range of carbon nanomaterials and needs no further oxidative treatment to these pristine carbons. Further improvement in performance can be potential achieved by optimizing the electrolyte composition (e.g. pyrrole concentration) and electrical parameters.
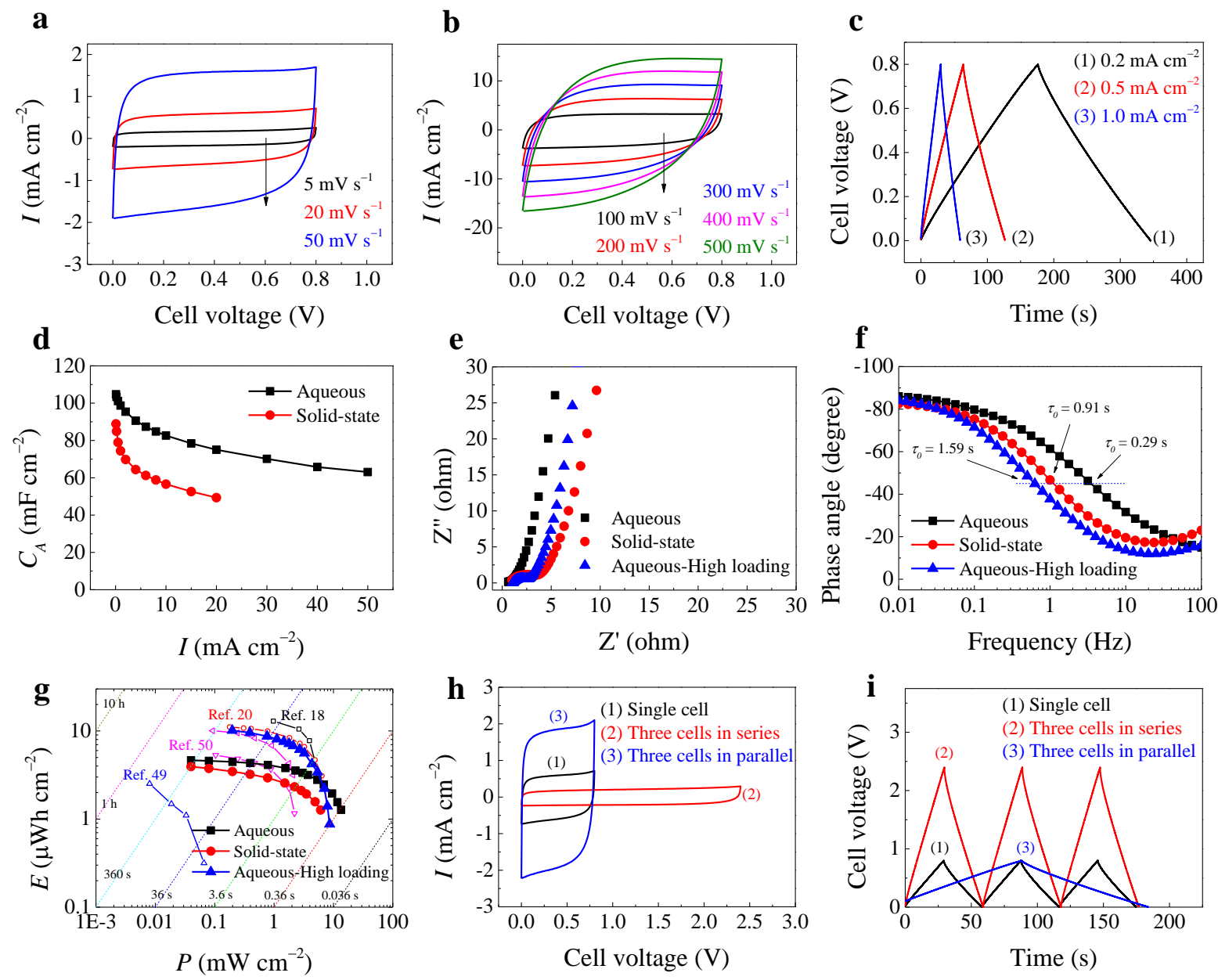

Figure 9. Electrochemical performance of the solid-state supercapacitor based on the PPy/EEG composite electrodes. (a) and (b) CVs for the solid-state device at various scan rates. (c) Galvanostatic charge-discharge curves for the solid-state device at different current 
densities. (d) Comparison of the rate capability for the aqueous and the solid-state supercapacitors. (e) Nyquist plots and (f) Bode plots of phase angle versus frequency for the aqueous, solid-state, and aqueous-high loading supercapacitors. (g) Ragone plots for the aqueous, solid-state, and aqueous-high loading devices, literature values are included for comparison. (h) CVs and (i) charge-discharge curves for the single cell, three cells in series and in parallel modules, respectively.

In order to demonstrate the potential of building energy storage modules with these solid-state single cells, modules of three cells in series and parallel has been assembled and tested, respectively. Figure $9 \mathrm{~h}$ and i show the CVs and galvanostatic charge-discharge curves for the single cell, three cells in series and in parallel, respectively. Clearly, all these supercapacitor systems work properly with ideal capacitive behaviour as evidenced by the rectangular shaped $\mathrm{CVs}$ and symmetric triangular shaped charge-discharge curves. Furthermore, as expected, the three cells in series module exhibit tripled cell voltage while the three cells in parallel module shows tripled capacitance (discharge time is three folds of the single cell).

\section{Conclusions}

In summary, a universal electrolyte formulation has been demonstrated for the electrodeposition of pristine carbon and PPy composite electrodes which solves the challenge of obtaining a good dispersion of carbon nanomaterials without compromising electrical conductivity through oxidation or ionic conductivity through large dopant, surfactant ions. The electrolyte features a quaternary formulation with $\mathrm{LiClO}_{4}$ as both supporting electrolyte and dopant, a trace amount of SDBS as surfactant, together with carbon nanomaterials and pyrrole 
monomers. This is attributed to the significant higher concentration of $\mathrm{ClO}_{4}{ }^{-}$anion $(20 \mathrm{mM})$ in the precursor electrolyte compared to the $\mathrm{DBS}^{-}$anion $(1.43 \mathrm{mM})$, thus the as-deposited PPy is predominantly doped by the smaller and more mobile $\mathrm{ClO}_{4}{ }^{-}$anions, leading to enhanced capacitance and rate capability. This approach has been used on a range of carbon materials, including carbon black, nanotubes and graphene. Moreover, the carbon composition in the composites can be controlled via the concentration of carbon in the precursor electrolyte, as demonstrated by the PPy/EEG system. The optimized PPy/EEG composite electrode shows a high specific capacitance of $348.8 \mathrm{~F} \mathrm{~g}^{-1}$ at $0.5 \mathrm{~mA} \mathrm{~cm}^{-2}$ and retains at $190.7 \mathrm{~F} \mathrm{~g}^{-1}$ at $20 \mathrm{~mA}$ $\mathrm{cm}^{-2}$. Both aqueous and solid-state supercapacitor devices have been fabricated and show ideal capacitive behaviors with high rate capability up to $500 \mathrm{mV} \mathrm{s}^{-1}$, and short time constant $<1 \mathrm{~s}$ ( $0.29 \mathrm{~s}$ for the aqueous device). Cycling stability test shows capacity retention of $94.3 \%$ after 5000 cycles. The approach reported here could be potentially suitable for the large-scale fabrication of pristine carbon and conducting polymer composite electrodes/coatings/films, for diverse applications not limited in energy storage.

\section{ASSOCIATED CONTENT}

\section{Support information}

The supporting information is available free of charge on the ACS publications website at DOI:

SEM images showing the effects of SDBS on the surface morphologies of the pure PPy and PPy/EEG composite electrodes; SEM images of the EEG flakes showing small debris with lateral size $<1 \mu \mathrm{m}$; the $\mathrm{N}_{2}$ adsorption and desorption isotherms and pore size distributions for 
EEG, PPy and PPy/EEG composite; comparison of CVs for the PPy and PPy/EEG-0.5 composite electrodes at different scan rate; galvanostatic discharge curves of the PPy/EEG composite electrodes at a current density of $1 \mathrm{~mA} \mathrm{~cm}^{-2}$; comparison of $\mathrm{CVs}$ and specific capacitances of PPy/EEG-0.5 electrodes with different deposition times of 600 and $1800 \mathrm{~s}$; CVs and charge-discharge curves of the aqueous-high loading supercapacitor fabricated with PPy/EEG-0.5-1800 s electrodes; comparison of electrochemical capacitance and cycling stability for various types of PPy based electrodes reported in literatures.

\section{AUTHOR INFORMATION}

\section{Corresponding author}

*Email: jianyun.cao@manchester.ac.uk; ian.kinloch@manchester.ac.uk

\section{Author Contributions}

The manuscript was written through contributions of all authors. All authors have given approval to the final version of the manuscript.

\section{Notes}

The authors declare no competing financial interests.

\section{ACKOWLEDGEMENT}

The authors are grateful to Morgan Advanced Materials/Royal Academy of Engineering, the Engineering and Physical Sciences Research Council (EPSRC), grant references 
EP/K016954/1, EP/R023034/1 and EP/L020742/1 for supporting this work. The EPSRC (UK) grants to the Sir Henry Royce Institute, grant references EP/S019367/1 and EP/P025021/1, are gratefully acknowledged.

\section{REFERENCES}

(1) Snook, G. A.; Kao, P.; Best, A. S. Conducting-Polymer-Based Supercapacitor Devices and Electrodes. J. Power Sources 2011, 196, 1-12.

(2) Huang, Y.; Li, H.; Wang, Z.; Zhu, M.; Pei, Z.; Xue, Q.; Huang, Y.; Zhi, C. Nanostructured Polypyrrole as a Flexible Electrode Material of Supercapacitor. Nano Energy 2016, 22, $422-438$.

(3) Meng, Q.; Cai, K.; Chen, Y.; Chen, L. Research Progress on Conducting Polymer Based Supercapacitor Electrode Materials. Nano Energy 2017, 36, 268-285.

(4) Wei, C.; Akinwolemiwa, B.; Yu, L.; Hu, D.; Chen, G. Z. 7 - Polymer Composites with Functionalized Carbon Nanotube and Graphene. In Polymer Composites with Functionalized Nanoparticles; Pielichowski, K.; Majka, T. M., Eds.; Elsevier: Amsterdam, 2019; pp 211-248.

(5) Winter, M.; Brodd, R. J. What Are Batteries, Fuel Cells, and Supercapacitors? Chem. Rev. 2004, 104, 4245-4269.

(6) Simon, P.; Gogotsi, Y. Materials for Electrochemical Capacitors. Nat. Mater. 2008, 7, 845-854.

(7) Wang, C.; Wang, S.; Tang, L.; He, Y.-B.; Gan, L.; Li, J.; Du, H.; Li, B.; Lin, Z.; Kang, F. A Robust Strategy for Crafting Monodisperse Li4ti5o12 Nanospheres as Superior Rate Anode for 
Lithium Ion Batteries. Nano Energy 2016, 21, 133-144.

(8) Griffith, K. J.; Wiaderek, K. M.; Cibin, G.; Marbella, L. E.; Grey, C. P. Niobium Tungsten Oxides for High-Rate Lithium-Ion Energy Storage. Nature 2018, 559, 556-563.

(9) Wu, X.; Hong, J. J.; Shin, W.; Ma, L.; Liu, T.; Bi, X.; Yuan, Y.; Qi, Y.; Surta, T. W.; Huang, W.; Neuefeind, J.; Wu, T.; Greaney, P. A.; Lu, J.; Ji, X. Diffusion-Free Grotthuss Topochemistry for High-Rate and Long-Life Proton Batteries. Nat. Energy 2019, 4, 123-130.

(10) Sabouraud, G.; Sadki, S.; Brodie, N. The Mechanisms of Pyrrole Electropolymerization. Chem. Soc. Rev. 2000, 29, 283-293.

(11) Peng, C.; Jin, J.; Chen, G. Z. A Comparative Study on Electrochemical Co-Deposition and Capacitance of Composite Films of Conducting Polymers and Carbon Nanotubes. Electrochim. Acta 2007, 53, 525-537.

(12) Cao, J. Y.; Wang, Y. M.; Chen, J. C.; Li, X. H.; Walsh, F. C.; Ouyang, J. H.; Jia, D. C.; Zhou, Y. Three-Dimensional Graphene Oxide/Polypyrrole Composite Electrodes Fabricated by One-Step Electrodeposition for High Performance Supercapacitors. J. Mater. Chem. A 2015, $3,14445-14457$.

(13) Chen, G. Z.; Shaffer, M. S. P.; Coleby, D.; Dixon, G.; Zhou, W. Z.; Fray, D. J.; Windle, A. H. Carbon Nanotube and Polypyrrole Composites: Coating and Doping. Adv. Mater. 2000, 12, $522-526$.

(14) Fan, L.-Z.; Maier, J. High-Performance Polypyrrole Electrode Materials for Redox Supercapacitors. Electrochem. Commun. 2006, 8, 937-940.

(15) Wang, J.; Xu, Y.; Yan, F.; Zhu, J.; Wang, J.; Xiao, F. Capacitive Characteristics of 
Nanocomposites of Conducting Polypyrrole and Functionalized Carbon Nanotubes: Effects of in Situ Dopant and Film Thickness. J. Solid State Electrochem. 2010, 14, 1565-1575.

(16) Chang, H.-H.; Chang, C.-K.; Tsai, Y.-C.; Liao, C.-S. Electrochemically Synthesized Graphene/Polypyrrole Composites and Their Use in Supercapacitor. Carbon 2012, 50, 2331-2336.

(17) Zhu, C.; Zhai, J.; Wen, D.; Dong, S. Graphene Oxide/Polypyrrole Nanocomposites: One-Step Electrochemical Doping, Coating and Synergistic Effect for Energy Storage. J. Mater. Chem. 2012, 22, 6300-6306.

(18) Zhou, H.; Han, G.; Xiao, Y.; Chang, Y.; Zhai, H.-J. Facile Preparation of Polypyrrole/Graphene Oxide Nanocomposites with Large Areal Capacitance Using Electrochemical Codeposition For supercapacitors. J. Power Sources 2014, 263, 259-267.

(19) Chen, J.; Wang, Y.; Cao, J.; Liu, Y.; Zhou, Y.; Ouyang, J. H.; Jia, D. Facile Co-Electrodeposition Method for High-Performance Supercapacitor Based on Reduced Graphene Oxide/Polypyrrole Composite Film. ACS Appl. Mater. Interfaces 2017, 9, 19831-19842.

(20) Zhou, H.; Zhai, H.-J.; Zhi, X. Enhanced Electrochemical Performances of Polypyrrole/Carboxyl Graphene/Carbon Nanotubes Ternary Composite for Supercapacitors. Electrochim. Acta 2018, 290, 1-11.

(21) Zhou, H.; Zhang, W.; Chang, Y.; Fu, D. Graphene Oxide Incorporated Polypyrrole Composite Materials: Optimizing the Electropolymerization Conditions for Improved Supercapacitive Properties. J. Mater. Sci.-Mater. Electron. 2019, 30, 1109-1116. 
(22) Österholm, A.; Lindfors, T.; Kauppila, J.; Damlin, P.; Kvarnström, C. Electrochemical Incorporation of Graphene Oxide into Conducting Polymer Films. Electrochim. Acta 2012, 83, 463-470.

(23) Deng, M.; Yang, X.; Silke, M.; Qiu, W.; Xu, M.; Borghs, G.; Chen, H. Electrochemical Deposition of Polypyrrole/Graphene Oxide Composite on Microelectrodes Towards Tuning the Electrochemical Properties of Neural Probes. Sens. Actuator B-Chem. 2011, 158, 176-184. (24) Li, X.; Zhitomirsky, I. Electrodeposition of Polypyrrole-Carbon Nanotube Composites for Electrochemical Supercapacitors. J. Power Sources 2013, 221, 49-56.

(25) Pérez Mañogil, P.; Fernández Romero, A. J. Influence of the Electrolyte Cation and Anion Sizes on the Redox Process of Ppy/Pvs Films in Acetonitrile Solution. J. Solid State Electrochem. 2010, 14, 841-849.

(26) Parvez, K.; Wu, Z. S.; Li, R.; Liu, X.; Graf, R.; Feng, X.; Mullen, K. Exfoliation of Graphite into Graphene in Aqueous Solutions of Inorganic Salts. J. Am. Chem. Soc. 2014, 136, 6083-6091.

(27) Su, C. Y.; Lu, A. Y.; Xu, Y. P.; Chen, F. R.; Khlobystov, A. N.; Li, L. J. High-Quality Thin Graphene Films from Fast Electrochemical Exfoliation. ACS Nano 2011, 5, 2332-2339.

(28) Cao, J.; He, P.; Mohammed, M. A.; Zhao, X.; Young, R. J.; Derby, B.; Kinloch, I. A.; Dryfe, R. A. W. Two-Step Electrochemical Intercalation and Oxidation of Graphite for the Mass Production of Graphene Oxide. J. Am. Chem. Soc. 2017, 139, 17446-17456.

(29) Pei, S.; Wei, Q.; Huang, K.; Cheng, H. M.; Ren, W. Green Synthesis of Graphene Oxide by Seconds Timescale Water Electrolytic Oxidation. Nat. Commun. 2018, 9, 145. 
(30) Tsai, I. L.; Cao, J.; Le Fevre, L.; Wang, B.; Todd, R.; Dryfe, R. A. W.; Forsyth, A. J. Graphene-Enhanced Electrodes for Scalable Supercapacitors. Electrochim. Acta 2017, 257, $372-379$.

(31) Chua, C. K.; Pumera, M. Chemical Reduction of Graphene Oxide: A Synthetic Chemistry Viewpoint. Chem. Soc. Rev. 2014, 43, 291-312.

(32) Brunauer, S.; Emmett, P. H.; Teller, E. Adsorption of Gases in Multimolecular Layers. $J$. Am. Chem. Soc. 1938, 60, 309-319.

(33) Lastoskie, C. M.; Gubbins, K. E. Characterization of Porous Materials Using Density Functional Theory and Molecular Simulation. In Stud. Surf. Sci. Catal.; Unger, K. K.; Kreysa, G.; Baselt, J. P., Eds.; Elsevier: Amsterdam, 2000; pp 41-50.

(34) Weidlich, C.; Mangold, K. M.; Jüttner, K. Eqcm Study of the Ion Exchange Behaviour of Polypyrrole with Different Counterions in Different Electrolytes. Electrochim. Acta 2005, 50, $1547-1552$.

(35) Skaarup, S.; Bay, L.; Vidanapathirana, K.; Thybo, S.; Tofte, P.; West, K. Simultaneous Anion and Cation Mobility in Polypyrrole. Solid State Ion. 2003, 159, 143-147.

(36) Liu, Y.; Zhang, D.; Pang, S.; Liu, Y.; Shang, Y. Size Separation of Graphene Oxide Using Preparative Free-Flow Electrophoresis. J. Sep. Sci. 2015, 38, 157-163.

(37) Diba, M.; Fam, D. W. H.; Boccaccini, A. R.; Shaffer, M. S. P. Electrophoretic Deposition of Graphene-Related Materials: A Review of the Fundamentals. Prog. Mater. Sci. 2016, 82, 83-117.

(38) Hontorialucas, C.; Lopezpeinado, A. J.; Lopezgonzalez, J. D. D.; Rojascervantes, M. L.; 
Martinaranda, R. M. Study of Oxygen-Containing Groups in a Series of Graphite Oxides Physical and Chemical Characterization. Carbon 1995, 33, 1585-1592.

(39) Zhang, J.; Zhao, X. S. Conducting Polymers Directly Coated on Reduced Graphene Oxide Sheets as High-Performance Supercapacitor Electrodes. J. Phys. Chem. C 2012, 116, $5420-5426$.

(40) Chen, G. Z. Understanding Supercapacitors Based on Nano-Hybrid Materials with Interfacial Conjugation. Prog. Nat. Sci. 2013, 23, 245-255.

(41) Neoh, K. G.; Lau, K. K. S.; Wong, V. V. T.; Kang, E. T.; Tan, K. L. Structure and Degradation Behavior of Polypyrrole Doped with Sulfonate Anions of Different Sizes Subjected to Undoping Redoping Cycles. Chem. Mater. 1996, 8, 167-172.

(42) Yang, X.; Cheng, C.; Wang, Y.; Qiu, L.; Li, D. Liquid-Mediated Dense Integration of Graphene Materials for Compact Capacitive Energy Storage. Science 2013, 341, 534-537.

(43) Li, Z.; Cai, J.; Cizek, P.; Niu, H.; Du, Y.; Lin, T. A Self-Supported, Flexible, Binder-Free Pseudo-Supercapacitor Electrode Material with High Capacitance and Cycling Stability from Hollow, Capsular Polypyrrole Fibers. J. Mater. Chem. A 2015, 3, 16162-16167.

(44) Jian, X.; Li, J.; Yang, H.; Cao, L.; Zhang, E.; Liang, Z. Carbon Quantum Dots Reinforced Polypyrrole Nanowire Via Electrostatic Self-Assembly Strategy for High-Performance Supercapacitors. Carbon 2017, 114, 533-543.

(45) Xu, L.; Jia, M.; Li, Y.; Zhang, S.; Jin, X. Design and Synthesis of Graphene/Activated Carbon/Polypyrrole Flexible Supercapacitor Electrodes. RSC Adv. 2017, 7, 31342-31351.

(46) Zhuo, H.; Hu, Y.; Chen, Z.; Zhong, L. Cellulose Carbon Aerogel/Ppy Composites for 
High-Performance Supercapacitor. Carbohydr. Polym. 2019, 215, 322-329.

(47) Lu, X.; Yu, M.; Wang, G.; Tong, Y.; Li, Y. Flexible Solid-State Supercapacitors: Design, Fabrication and Applications. Energy Environ. Sci. 2014, 7, 2160-2181.

(48) Zhou, H.; Han, G.; Fu, D.; Chang, Y.; Xiao, Y.; Zhai, H.-J. Petal-Shaped Poly(3,4-Ethylenedioxythiophene)/Sodium Dodecyl Sulfate-Graphene Oxide Intercalation Composites for High-Performance Electrochemical Energy Storage. J. Power Sources 2014, 272, 203-210.

(49) Wei, H.; Zhu, J.; Wu, S.; Wei, S.; Guo, Z. Electrochromic Polyaniline/Graphite Oxide Nanocomposites with Endured Electrochemical Energy Storage. Polymer 2013, 54, $1820-1831$

(50) Zhou, H.; Han, G. One-Step Fabrication of Heterogeneous Conducting Polymers-Coated Graphene Oxide/Carbon Nanotubes Composite Films for High-Performance Supercapacitors. Electrochim. Acta 2016, 192, 448-455. 


\section{For Table of Contents Only}

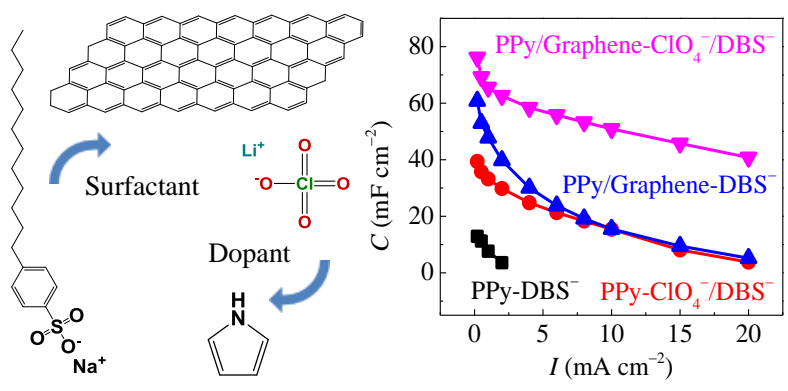

